\title{
AN INTRODUCTION TO UNIPOLAR LEAD CARDIOGRAPHY
}

\author{
By Samuel Oram, M.D., M.R.C.P. \\ Assistant Physician, King's College Hospital, London
}

The following account of unipolar lead cardiography has been prompted by the convictions that it is a more scientific method of studying the action currents generated by the heart than the more usual but empirical bipolar lead method, and that it has very considerable clinical advantages of value to both patient and clinician.

\section{Theoretical Considerations}

It is necessary to consider in some detail the electrical events that occur when an impulse travels across a cell. All active cells produce electrical currents, and the current-producing force, or electro-motive force, can be detected by means of a galvanometer. The electrocardiograph is simply a galvanometer which is calibrated to measure volts, and the convention is to magnify the deflection of its string in such a manner that when I mv. passes through the fibre its shadow moves $\mathrm{I} \mathrm{cm}$. The circuit is so arranged that a positive potential causes an upward deflection. A resting cell can be considered as being enclosed in a semi-permeable membrane which permits the positive ions (cations) to migrate outward but which leaves the larger negative ions (anions) inside the cell. According to the laws governing the distribution of electrolytes on both sides of a semi-permeable membrane, equilibrium will be established between these ions, and when the cell is resting or 'polarized' the positive ions outside the cell exactly balance the negative ions inside and no potential is measurable. Thus the ions can be considered as pairs, each pair consisting of one negative pole and one positive pole. These pairs are known as dipoles, doublets, or couplets. Now when the surface of a cell is stimulated locally, the permeability of its wall in this region becomes negative by allowing negative ions to migrate through it, and this wave of negativity, preceded always by a wave of positivity, passes across the cell. This wave can be represented by an arrow, the head of which is positive and the tail negative. The spread of the excitation wave is called activation or depolarization, and the junction between the stimulated region and the region about to be stimulated is called the boundary of potential difference. The effect is as though the dipoles spread with the positive pole, or source, preceding the negative pole, or sink. The recovery process, or reformation of the dipoles, is called repolarization, and can take place either in the same direction as the destruction of the dipoles during depolarization, or in the opposite direction.

The validity of this doublet or dipole hypothesis, as it is known, has been established by, among others, Ashman, Wilde and Drawe (1940), and it can be extended to apply not only to a simple strip of muscle but to the syncytium of the heart. It must be constantly borne in mind however, that the heart consists of a most complicated laminatedo cup-shaped muscle divided unequally by a sep-? tum, and that it is continuously moving in three planes.

Let us consider first a simple muscle strip (Fig. I). At A a resting, or polarized, cell is depicted. In $B$ a stimulus has been applied at the left side of the strip and the impulse is beginning to travel in the direction shown by the arrow. The shaded area represents the part of the strip which has become depolarized ; the boundary of potential difference is seen. In $\mathrm{C}$ depolarization has occurred. D shows the stimulated strip returning to the resting state in the same direction as stimulation occurred, and in $\mathrm{E}$ complete repolarization has occurred. It is seen from the diagrams that an electrode facing the right hand surface of the strip will inscribe an upward deflection during depolarization and a downward deflection during repolarization. But in the human heart stimulated muscle returns to the resting state in a different direction from that in which it was stimulated, and it will be seen from the diagrams $D^{1}$ and $E^{1}$ that when that is so the repolarization wave will point in the same direction as the depolarization wave. That is to say, in human electrocardiography the RS-T segment and the T-wave will point in the same direction as the QRS complex. Wilson and others (1947) have pointed out that the inscription 


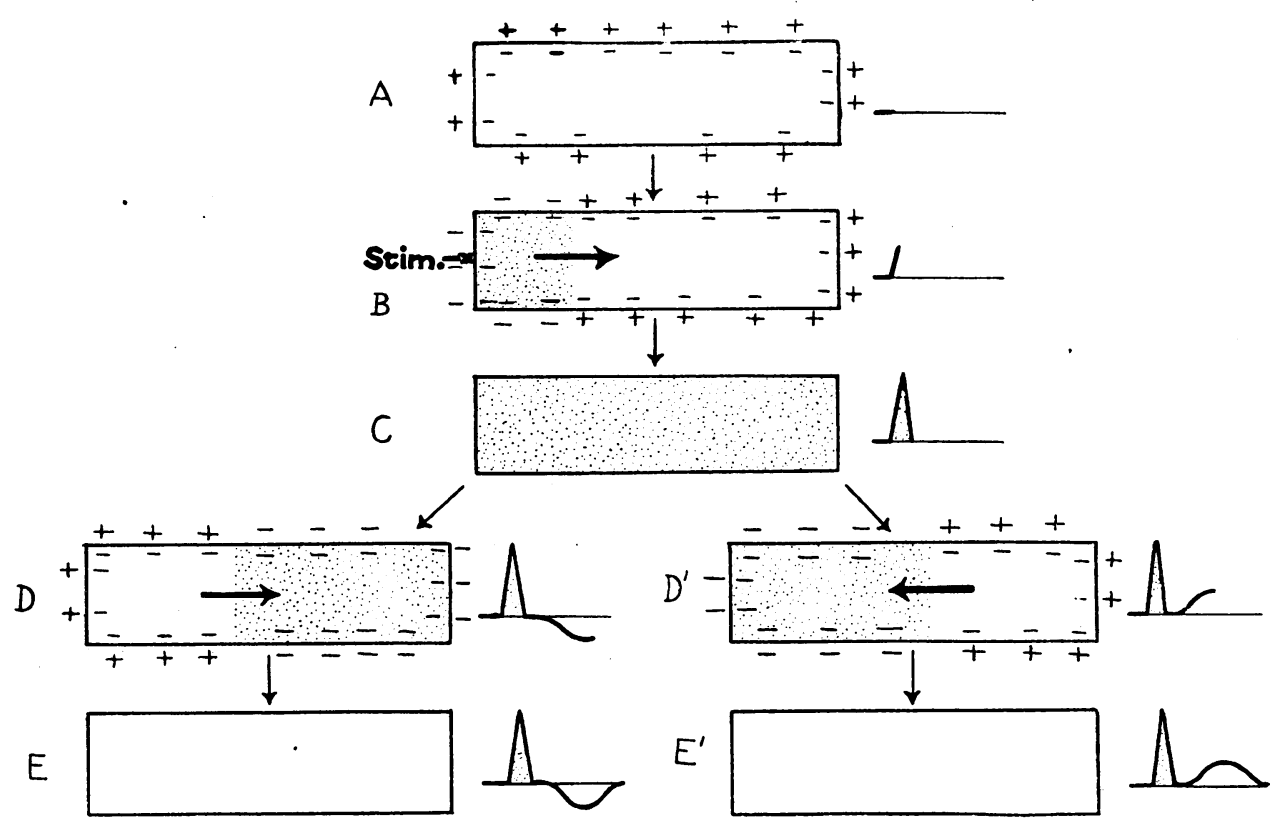

Fig. 1.-A to $\mathrm{C}$ represent, in diagrammatic form, the inscription of the depolarization wave. $\mathrm{D}$ and $\mathrm{E}$ depiet the formation of the repolarization wave in a simple muscle strip, and $D^{\prime}$ and $E^{\prime}$ represent its formation in the human heart.

of the T-wave necessarily begins before the QRS tracing has finished because repolarization begins before the muscle previously activated is completely depolarized. This overlap of the QRS and $\mathrm{T}$ affects the position of the RS-T junction, and when the QRS interval is long there is great overlapping. It is therefore not surprising that conditions with a long QRS interval such as bundlebranch block and left ventricular hypertrophy result in considerable displacement of the RS-T junction.

The contour of the muscle from which the electrode is picking up current does not affect the magnitude of the electro-motive force recorded. In Fig. 2, if the lines are extended from the edges of the muscle $(M)$ to meet at $P$ in the centre of a sphere of unit area (s), a solid angle which is coneshaped (c) will be formed at $\mathrm{P}$, and the area (a) on the surface of the sphere (s) cut off by this cone is proportional to the magnitude of the deflection. In Fig. $2 b$ it is clearly seen that any surface irregularity does not affect this statement and the areas $a$ and $a^{l}$ are identical.

If two electrodes from the galvanometer are placed either directly on the heart or, as in clinical practice, on the body, which may be regarded as a conducting medium from the heart, they will record potential variations that occur beneath each of them. Such an arrangement is used, of course, in recording the standard leads of bipolar cardiography (Fig. 3a). Lead I is produced by currents recorded from the right arm (R.A.) and left arm (L.A.), Lead II from the right arm and left leg (L.L.), and Lead III from the left arm and left leg. The direction of spread of the impulse across the heart during depolarization can be represented by arrows as previously described, and it will be seen that current will flow from R.A. to L.A., from R.A. to L.L., and from L.A. to L.L. It is seen from the diagram that Lead $I=L$.A. - R.A., Lead II = L.L.-R.A. and Lead III = L.L.-L.A. Thus, because for example in Lead I, the deflection represents the difference between the potential at the right arm and left arm, it gives no indication of the actual potential at either arm. It will be seen that it is possible to obtain an upward deflection in Lead I whenever the potential at the left arm is either more positive or less negative than that at the right arm. Similarly a positive wave in I.eads II and III simply means that the left leg is more positive or less negative than the ' right arm if Lead II is considered or the left arm if 


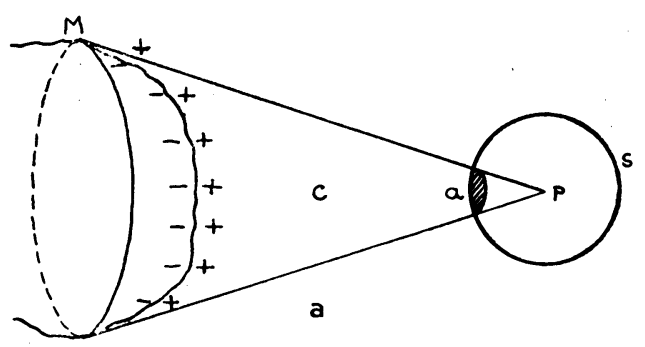

placed on the same plane as the muscle and equidistant from each other and from the muscle. It can be proven mathematically that the algebraic sum of their potentials at any instant will be zero. Therefore, if the three electrodes are connected to a central terminal, $\mathrm{C}$, the potential of that terminal will be zero and it can be used as an indifferent electrode. Unipolar leads can be taken by connecting the electrocardiograph to the central terminal and to an exploring electrode.

Now the Einthoven triangle theory, enunciated as long ago as, 1913 , renders it possible to apply the above reasoning to human recording, and although there have been many objections to this theory both Wilson (1946) and Goldberger (1945) uphold it. Its assumptions are justified in clinical cardiography. Those assumptions are, first, that the electrical activity of the heart is assumed to be like a single battery situated in the centre of the body ;

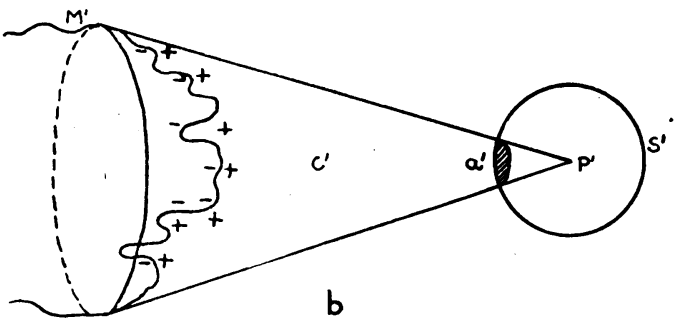

FIG. 2.-This illustrates how surface irregularity of muscle does not influence the magnitude of the cardiograph deflection. For further description see text.

Lead III is concerned. Thus a positive wave as recorded by bipolar leads can arise in three quite different ways, namely, as a result of the difference between two positive waves, or the difference between a positive and negative wave, or the difference between two negative waves. This is shown in Fig. $3 \mathrm{~b}$, where purely arbitrary units have been chosen. If these facts are not appreciated, serious errors in the interpretation of bipolar lead cardiograms will occur.

It is thus desirable that the electrical activity of one portion only of a muscle should be studied at any one instant, particularly one of such complicated form as the heart. In the standard or bipolar leads, the picture which results from an admixture of potentials from the right and left heart is too composite for simple analysis. In so-called ' unipolar lead' cardiography, although two electrodes are, of course, employed, the electrical activity beneath one electrode only is recorded. Actually, there is always some fusion of potential from both electrodes, but arrangement is made whereby the potential recorded by one electrode is rendered negligible. This is called the indifferent electrode, and the recording one is known as the exploring electrode.

In Fig. $4 \mathrm{a}$ a small amount of muscle $(\mathrm{M})$ is considered to be in the centre of a large circular container, and at $E_{1}: E_{2}$ and $E_{3}$ electrodes are
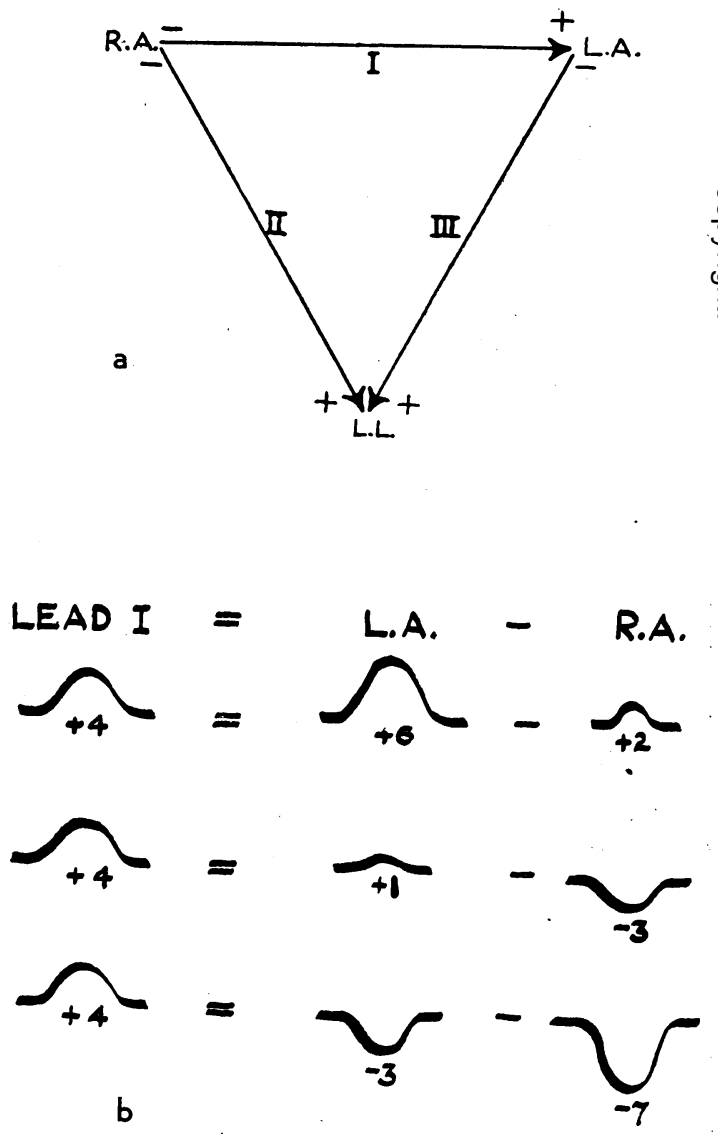

FIG. 3.-A represents the arrangement for recording. the standard leads of bipolar cardiography. B illustrates three different ways in which the $T$ wave in Lead I may be formed. 


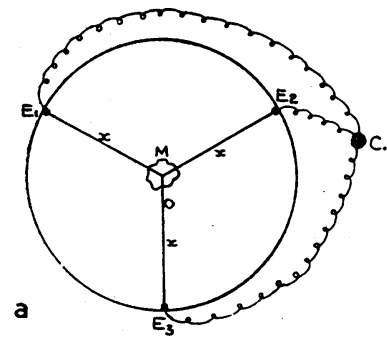

-

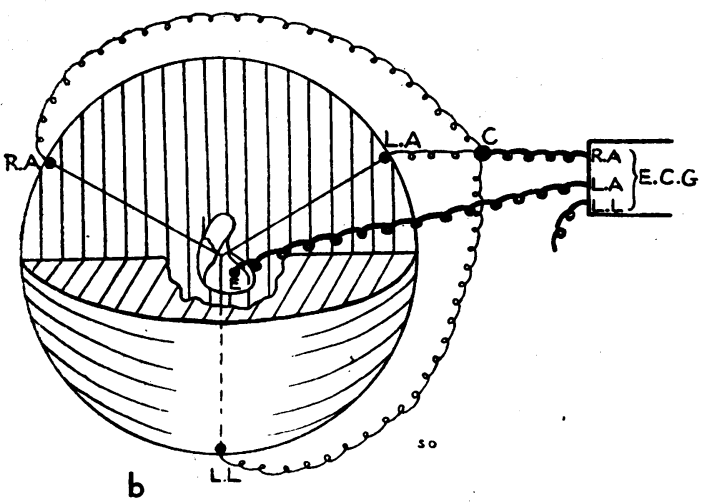

FIG. 4.-A shows the connections to a central terminal of zero potential. $B$ illustrates the manner in which the central terminal and the exploring electrode are connected to the cardiograph, which is used with the switch in the 'Lead I' position.

secondly, that the shape of the body is spherical and the tissues have similar resistances; thirdly, that the right arm, left arm and left leg are equidistant from each other and from the heart ; and last, that the heart and the limbs lie on one plane which in man is frontal. In Fig. $4 \mathrm{~b}$ this arrangement is shown diagrammatically. The heart is represented as being surrounded at the centre of a sphere, part of which has been cut away. The electrocardiograph machine is set as if recording Lead I (R.A. and L.A.). The R.A. wire is joined to the central terminal, $\mathrm{C}$, of zero potential. Then the left arm wire from the machine can be used as an exploring electrode (E) which will be unipolar. This is actually done in clinical practice in recording the chest leads, but if such an arrangement is used for recording the limb lead potentials the amplitude of the deflection is inconveniently small for clinical work. Recently, Goldberger (I942 (i)) made a most useful contribution to cardiography. He showed that by leaving unconnected from the patient the one of the three wires leading to the central zero terminal which would be coming from the limb which would also be receiving the exploring electrode, the deflections were increased by exactly 50 per cent. The machine is standardized in the same way as for standard leads (Fig. 5 b). He called these leads augmented unipolar limb leads and suggested that the one from the right arm be cálled $\mathrm{aVR}$, from the left arm aVL, and from the left foot aVF, in conformity with Wilson's suggestion of 1934 that unipolar leads should be called $\mathrm{V}$ leads ( $\mathrm{V}$ for voltage). In practice nowadays the a for augmented is dropped. This Goldberger technique is unnecessary in the case of chest leads as the voltage is so high, in fact at times the fibre sensitivity has to be reduced to a half $(\mathrm{N} / 2)$ or even one-third $(\mathrm{N} / 3)$. Wilson and his co-workers (1934) originally stated that, on theoretical grounds, each lead leading to the central zero terminal should have interposed in it a resistance of $5,000 \mathrm{ohms}$. If this is done it has been shown by Wilson, et al. (1946) that the potential of this so-called zero terminal is in fact never greater than $0.3 \mathrm{mv}$., and this is negligible clinically (Fig. 5a). However, Goldberger (I942 (ii)) published tracings taken with both his and Wilson's technique and they were identical in form, and this was confirmed by Johnston, et al. (1943).

Wilson recommended that six positions acros the chest should be used as routine, and in 1938 the American Heart Association accepted hiș recommendations. The six positions are known as $\mathrm{V}_{1}, \mathrm{~V}_{2}, \mathrm{~V}_{3}, \mathrm{~V}_{4}, \mathrm{~V}_{5}$ and $\mathrm{V}_{6}$. In addition, three other leads are commonly used on the chest and are known as V7, V8 and VE. For position VI the electrode is placed in the fourth intercostal space just to the right of the sternum ; the position of $\mathrm{V}_{2}$ is in the fourth intercostal space just to the left of the sternum; $V_{3}$ is mid-way between $V_{2}$ and $\mathrm{V}_{4} ; \mathrm{V}_{4}$ is in the fifth left intercostal space in the mid-clavicular line; $\mathrm{V}_{5}$ is in the left anterior axillary line at the level of $\mathrm{V}_{4} ; \mathrm{V} 6$ is in the left mid-axillary line at the level of $\mathrm{V}_{4} ; \mathrm{V}_{7}$ is in the left posterior axillary line at the level of $\mathrm{V}_{4} ; \mathrm{V} 8$ is placed directly under the angle of the left scapula; VE is recorded from the tip of the ensiform cartilage.

There have been several suggestions recently that, as the indifferent electrode in bipolar chest leads picks up such a small potential, in practice the differences between the complexes of CR, CF and $\mathrm{V}$ chest leads are negligible. Some workers, notably Evans (1948), still prefer CR leads. Wilson (1944) has estimated that the size of the deflections obtained from the chest is about four times that of the extremities. The influence of the limb electrode is therefore about a quarter that of the chest electrode. Thus in Lead CR, where the indifferent electrode is attached to the right 

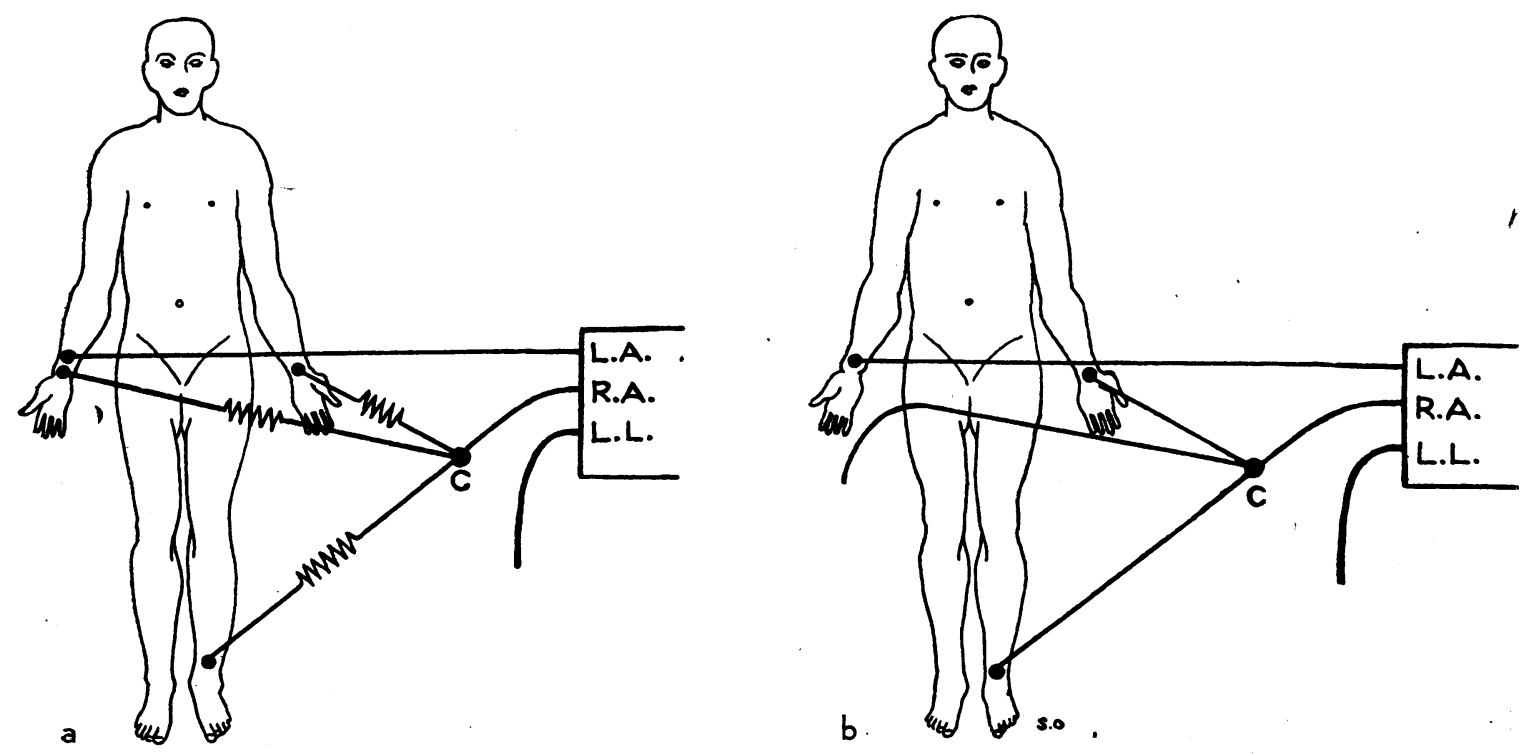

Fig. 5.-A, Wilson's original method of rec-rding unipolar leads. B, Goldberger's arrangement for obtaining augmented unipolar leads. In both figures the connections are depicted as for recoraing Lead VR.

arm, the deflection equals approximately $\mathrm{C}-\frac{\mathrm{VR}}{4}$, or, if Golberger's technique is used, $\mathrm{CR}=$ $\mathrm{C}-\frac{\mathrm{VR}}{6}$. Similarly, $\mathrm{CF}=\mathrm{C}-\frac{\mathrm{VF}}{6} . \quad$ Bain and Redfern (1948) examined 300 limb leads with regard to this point, and although in 89 per cent. the distortion was negligible, being not more than $0.5 \mathrm{~mm}$., in the remaining I I per cent. it was appreciable. For example, they illustrate a case which in the V leads showed left ventricular hypertrophy but which the CR leads showed as normal. Another case showing evidence of anterior infarction in $\mathrm{V}$ and $\mathrm{CF}$ leads did not show it in $\mathrm{CR}$ leads. In $\mathrm{CR}$ the distortion is greatest in semihorizontal or semi-vertical positions. CF distortion is greatest in the vertical position. Inverted $T$ waves may be recorded in CF leads if the heart is vertical owing to negative distortion from the left leg. Negative $T$ waves may appear as positive in Lead CR because of the influence of the right arm.

From the foregoing it will be seen that the two main factors influencing the form of unipolar lead tracings are the direction of spread and return of the impulse, and the location of the electrode in regard to the position and distance from the muscle. If the spread of the impulse is represented by the arrow described above, and the electrode is facing the head of the arrow, the machine will record an upward QRS complex. If the impulse is spreading away from the electrode QRS will be 0 downward. When an impulse spreads at right angles away from the electrode no potential wilko be recorded. As Goldberger (1944) has em-phasized, apart from the direction of spread of the impulse, the actual muscle mass must be considered. When impulses from two regions spread in the same direction their effect on a unipolar electrode will be summated, but if they spread in opposite directions they will tend to cancel each other and the stronger one will predominate.

There is a simple relationship between unipolar and bipolar leads :-

$$
\begin{aligned}
\text { Lead I } & =\text { LA-RA, } \\
\text { Lead II } & =\text { LL-RA, } \\
\text { and Lead III } & =\text { LL-LA. }
\end{aligned}
$$

Thus Lead I tends to resemble the LA lead, or the reverse of the RA lead. Lead II tends to resemble the LL lead or the reverse of the RA lead. Lead III tends to resemble the LL lead or the reverse of the LA lead.

It can be shown by using Goldberger's augmented limb lead technique that :-

$$
\begin{gathered}
\mathrm{aVR}=-\frac{\mathrm{I}+\mathrm{II}}{2}, \\
\mathrm{aVL}=\frac{\mathrm{I}-\mathrm{III}}{2}, \\
\mathrm{aVF}=\frac{\mathrm{II}+\mathrm{III}}{2} .
\end{gathered}
$$




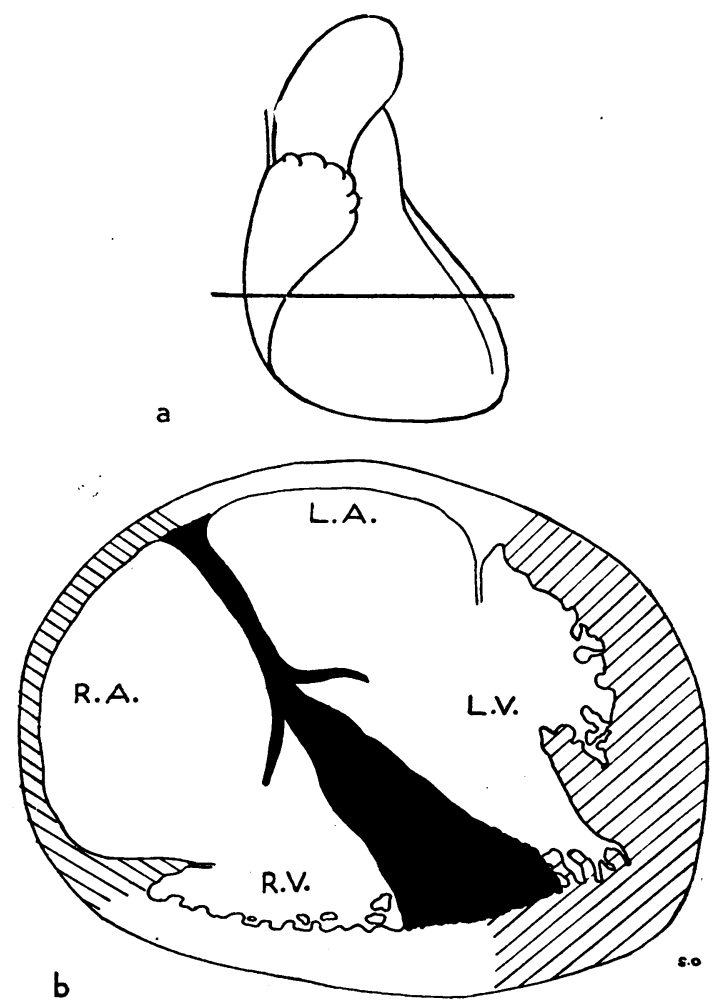

Fig. 6.-A indicates the level of transverse section $B$. Most of the ront of the heart consists of right ventricle, the back left auricle, the right border right auricle, and the left border left ventricle (after Eycleshymer and Shoemaker).

\section{Basic Normal V Lead Patterns}

The importance of Goldberger's conception is that once the basic pattern given by a known surface of the heart is recognized, it can be assumed that whenever a similar pattern is found in any of the limb leads, that limb must face the known surface. Wilson has issued a warning that the interpretation of $\mathrm{V}$ lead deflections obtained from body surfaces according to the principles of those obtained direct from the pericardium is open to serious error if the distance between the exploring electrode and epicardium is great.

There is some evidence that the cardiogram from the auricles resembles that obtained from a simple muscle strip, but usually the $T$ wave of the auricle, or Ta wave, is encroached on or hidden within the ventricular complex.

Cardiographically, the ventricles can be regarded as an asymmetrical cup the mouth of which faces the right shoulder. It is made up of three muscle groups-the right ventricle, septum and left ventricle. The left ventricle is larger and thicker than the right. The right ventricle faces the anterior chest wall, but very little of it, if any, lies to the right of the sternum. Most of the left ventricle lies over the diaphragm. The left auricle constitutes most of the base or posterior aspect of the heart. In man the name 'left auricle' is a misnomer and it would be better called the 'posterior auricle.' The long axis of the heart, from base to apex, runs obliquely forward, downward and to the left. The ventricular septum also lies obliquely, its right ventricular surface facing anteriorly and to the right, and the left ventricular surface facing posteriorly and to the left. Fig. 6, modified from Eycleshymer and Shoemaker (I9II), shows how in a transverse section of the heart along the line indicated in A most of the front wall of the heart is made up of right ventricle, posterior wall by left auricle, right wall by right auricle, and left wall by left ventricle.

Every unipolar lead records potentials from each of all three muscle groups, and Goldberger advises the use of five fundamental positionsfacing the left ventricle (therefore facing also the left side of the septum and the endocardial surface of the right ventricle); facing the right ventricle (therefore facing also the right side of the septum and the endocardial surface of the left ventricle); facing the cavity of the right ventricle ; facing the cavity of the left ventricle ; and facing the back of the heart. The first three, for ordinary clinicafo purposes, are covered respectively by Leads $\mathrm{V}_{4}$ $\mathrm{V}_{5}$ and $\mathrm{V}_{6} ; \mathrm{V}_{1}, \mathrm{~V}_{2}$ and $\mathrm{V}_{3}$; and $\mathrm{VR}$. In addition VL and VF are taken. The latter two are composite leads and, as will be seen later, are greatly influenced by the heart's position.

In Fig. 7 is illustrated the genesis of curves obtained in position VR, in positions $V_{I}$ and $V_{2}$ to the right of the septum, and positions $\mathrm{V}_{5}$ and V6 to the left of the septum. It will be sufficient if the method of calculating the deflection obtained in Leads $\mathrm{V}_{5}$ and $\mathrm{V} 6$ is explained, as similar reasoning can be applied to electrodes situated in any other position. It will be seen from Fig. $7^{\mathrm{a}}$ that in the $\mathrm{V}_{5}$ and $\mathrm{V} 6$ position the initial deflection is downward. This is due to the fact that, according to Gardberg and Ashman (1943), the left side of the septum is stimulated first and impulses spread through the ventricular septum from left to right. The electrode therefore faces the negative tail. From Fig. $7 \mathrm{~b}$ it will be seen that the electrical potentials produced by the left ventricle are greater than those of the right ventricle, and as the left ventricular impulse will give an upward deflection and the right ventricle would tend to cancel this, the resultant of these two opposite forces will give an upward deflection. This may be followed by a small negative wave, which is probably due to the fact that the last region to be stimulated in the heart is a portion of the right ventricle. The form of complexes from the left 
side of the heart is therefore QR or QRS. From similar reasoning it can be calculated that Leads $V_{I}$ and $V_{2}$ will give normally an RS pattern or, occasionally, an RSR pattern. Thus, as the electrode is moved across the heart from the right to the left, the $R$ wave, which in $V_{I}$ and $V_{2}$ is about half the amplitude of the $\mathrm{S}$ wave, becomes taller, and the $\mathrm{S}$ wave becomes smaller and has disappeared generally in Leads $\mathrm{V}_{5}$ and V6. The point where $R$ and $S$ are of equal but opposite amplitude is called the transitional point, and corresponds approximately to the position of the ventricular septum. The features then of the normal precordial electrocardiogram are that that size of $R$ increases steadily from $V_{I}$ to $V_{4}$, and then decreases to V6. The peak of it falls early in the QRS interval in $V_{1}$ and $V_{2}$ and about 0.03 sec. later in $\mathrm{V}_{5}$ and $\mathrm{V} 6$. $\mathrm{S}$ is large in " rightsided' electrodes and small in 'left-sided' electrodes, when the former term is taken to imply
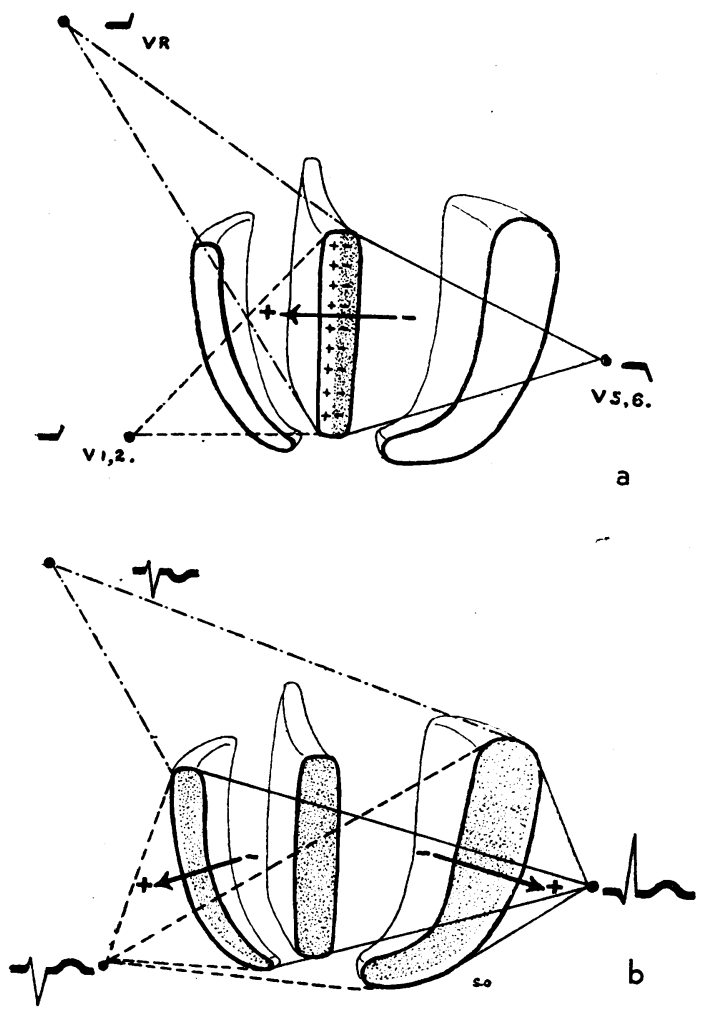

Fig. 7.-A represents the passage of an impulse (denoted by stippling) across the septum as recorded from the right arm and right and left sides of the heart. B depicts the completed tracings at these three sites (modified from Goldberger). positions to the right of the transitional point and the latter indicates points to the left of it. Nearly always there is a small $Q$ wave in V6. Normally, the $\mathrm{T}$ waves are upright, but $\mathrm{T}$ in $\mathrm{V}_{I}$ is frequently inverted in health and, if the heart is vertical, $V_{2}$ may also be inverted. In children only, inversion in $V_{3}$ may be found in health. The location and width of the transitional zone is very variable, and it is not always spanned by the usual VI to V6 leads. In that case, if accurate information is required concerning the position of the heart, leads from points farther to the right or left must be taken. Wilson has pointed out that even this may be insufficient if the transitional zone is displaced upwards or downwards. The term 'intrinsic deflection,' which was introduced by Lewis and Rothschild (1915), is used to denote the moment when the impulse spreading outwards through the ventricular wall reaches the sub-epicardial muscle. It begins at the peak of the $R$ wave and ends either at the iso-electric level or at the nadir of the $\mathrm{S}$ wave ; it will be referred to later when ventricular hypertrophy is discussed.

It can be seen that an electrode from the right arm (VR) faces the cavity of the right ventricle and will give an RS pattern. Sodi Pallares, et al. (I947) have shown that this RS pattern does appear if the electrode is actually inserted into the right ventricular cavity.

An electrode facing the back of the heart gives a QR deflection.

\section{Effects of Altering the Position of the Heart}

We are now in a position to be able to study the effects of alterations in the position of the heart on the form of the cardiogram. There has been considerable controversy concerning this matter, and Durant (I948) has suggested that Goldberger has extended his positional theories too far. Durant states that experimental work with direct leads in animals, and studies of the transitional zone in humans, are not in accord with the statement that the entire left ventricle gives rise to $Q R$ or $Q R S$ patterns in $\mathrm{V}$ leads that face its epicardial surface, and that only the lateral and posterobasal portions of it give an initial negative deflection in the normal heart.

The position of the heart in the chest can vary in three ways-it can rotate around the anteroposterior axis so that its long axis becomes horizontal if it rotates to the left or vertical if it rotates to the right. This is the most obvious positional alteration and Master (I942) has published a book in which he correlates the X-ray appearance of the heart with the form of the cardiogram. The second alteration of position is rotation around its long axis. If the heart is looked at from the apex 
towards its base, it can rotate either in a clockwise or anti-clockwise direction. A vertical heart usually, although not always, shows some degree of clockwise rotation, so that the right ventricle becomes more anterior and the left ventricle more posterior, the septum being displaced to the left. A horizontal heart more commonly shows anticlockwise rotation, which causes the left ventricle to become anterior and the septum to be displaced to the right. It may be found helpful to employ a ' corkscrew' simile. The rotation of the heart around its long axis is likened to a cork being drawn from a bottle, the bottle being held with the left hand by its neck with its base away from the observer. Then if a corkscrew is screwed in with the right hand whilst the cork is drawn, the bottle and cork will become 'longer' (more vertical) and the right hand will turn clockwise. Although, as we shall see, cardiographic interpretation of cardiac rotation of this type is fairly reliable, radiographic confirmation is at present difficult or impossible. The third axis around which the heart can rotate is the transverse one, the apex becoming nearer to the anterior chest wall in forward rotation and farther away in backward rotation. Again, it is at present impossible to correlate this radiographically, but to the author it would seem that this extension of Goldberger's positional theories is a reasonable one although as yet it lacks proof.

Rotation around the A.P. axis. Wilson and others (I944) have used the variable relationships between the V limb and V chest leads to define six cardiographic positions of the heart. During the past few years these workers have been criticized on the grounds that strict anatomical correlation with these positions is not always found. But last year Wilson and his co-workers (1947) published a very clear statement which is worth quoting:- "The names given to these positions are not intended to imply that the electrocardiographic position of the heart is uniquely determined by its anatomic position, either when this organ is normal or abnormal. We are not only aware, but are also certain, that a change in the one is not necessarily accompanied by a change in the other.'

The six positions described are :-

I. Vertical position.

(i) The ventricular complexes in VL resemble $\mathrm{V}_{\mathrm{I}}$ and $\mathrm{V}_{2}$.

(ii) The ventricular complexes of VF resemble $\mathrm{V}_{5}$ and $\mathrm{V} 6$.

2. Semi-vertical position.

(i) The ventricular complex of VF resembles $\mathrm{V}_{5}$ and V6.

(ii) The QRS of VL is small.

3. Intermediate position. The ventricular com- plexes of VL and VF are similar in form and size and resemble $\mathrm{V}_{5}$ and $\mathrm{V} 6$.

4. Semi-horizontal position.

(i) The ventricular complex of VL re- $\frac{a}{c}$ sembles $\mathrm{V}_{5}$ and $\mathrm{V} 6$.

(ii) The ventricular complex of VF is small. $\stackrel{\overrightarrow{\vec{S}}}{\vec{f}}$

5. Horizontal position.

(i) The ventricular complex of VL resembles $\mathrm{V}_{5}$ and $\mathrm{V} 6$.

(ii) The ventricular complex of VF re- $\frac{\mathbb{Q}}{2}$ sembles VI and V2.

6. Indeterminate position. There is no obvious क relationship between the ventricular complexes of the limb leads and those of the precordial leads.

Actually Goldberger's criteria for the determination of the position of the heart are not $\overline{8}$ identical with those of Wilson. Goldberger argues 3 . that in a vertical heart much of the epicardial o surface of the left ventricle faces the left leg, there- i fore the form of VF is similar to that obtained from $\stackrel{\infty}{N}$ electrodes facing the left ventricle; VF thus $\vec{G}$ shows a QR complex with an upward $\mathrm{T}$ wave. $\vec{O}$ This criterion agrees with Wilson, and for practical $\frac{O}{2}$ purposes no other criteria are needed. Similarly, $\vec{\rightarrow}$ in a horizontal heart the left arm faces the surface $\frac{D}{0}$ of the left ventricle therefore Lead VL will show a QR pattern and, usually, an upward T wave. $\overrightarrow{0}$

In Fig. 8 the cardiogram of a vertical heart 8 shown, and this is also suggested by the standard. leads. It is seen that Lead III resembles VF. IO Fig. 9, from a semi-vertical heart, the standard leads give no indication that the heart is vertical. Fig. Io illustrates a horizontal heart-it is seen that Lead I resembles VL. Figs. II to I4 illustrate respectively a semi-vertical heart, semihorizontal heart, a heart in the intermediate position, and a heart whose position is indeterminate.

Rotation around the longitudinal axis. Normally the transitional point is between $\mathrm{V}_{3}$ and $\mathrm{V}_{4}$. In clockwise rotation it is shifted to the left, and in 3 . anti-clockwise rotation to the right (or right and 8 left respectively as seen in the cardiogram). In 3 extreme cases the front of the heart can face pos- 0 teriorly and the organ is literally 'back to front' as far as the ventricles are concerned. Fig. I 5 을 illustrates a heart with the normal amount of rotation around the longitudinal axis. The transitional $\widetilde{N}$ point is between $\mathrm{V}_{3}$ and $\mathrm{V}_{4}$. Fig. 16 illustrates a $\mathrm{N}$ considerable degree of clockwise rotation; the N transitional point is between $\mathrm{V}_{5}$ and V6. Fig. $\mathrm{I}_{7} \mathrm{~W}$ illustrates extreme clockwise rotation and no transitional point is seen. With such rotation, $\frac{0}{\Phi}$ downward T waves in Leads $\mathrm{V}_{I}-\mathrm{V}_{3}$ do not occur $\stackrel{0}{\rightarrow}$ although the reason for this is unknown. The left arm (VL) may in such a heart face the right ventricular cavity, and will therefore show an RS pattern and a downward $T$ wave. The $T \stackrel{\mathbb{D}}{\mathbb{Q}}$ 


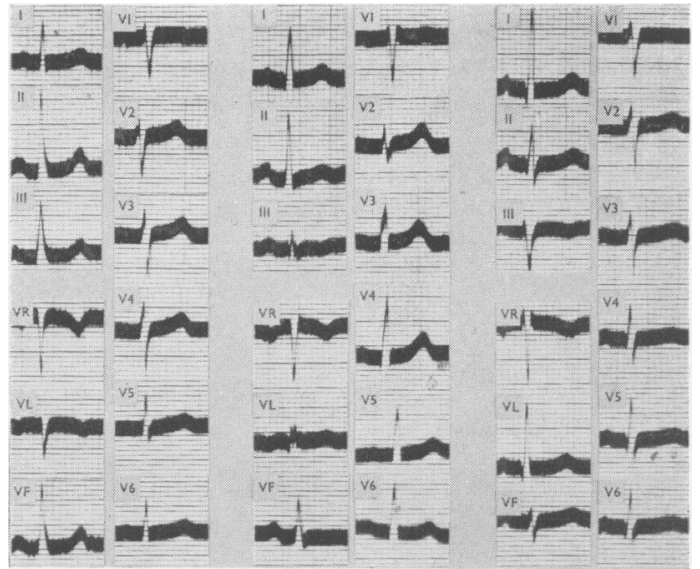

Fig. 8.-Vertical heart. The heart is seen to be in the vertical position electrically because Lead VF shows a tall $R$ wave and Lead VL a deep $S$ wave. Also, the form of VF resembles that of V6.

FIg. 9.-Semi-vertical heart. The heart is semivertical because although there is a tall $R$ wave in Lead VF the complexes of VL are small. The standard leads give no indication that the heart is vertical.

FIg. 10.-Horizontal heart. The heart is horizontal because the $R$ wave is tall in VL and the $S$ wave is deep in VF. Also, the form of VL resembles that of $V_{5}$ and $V 6$.

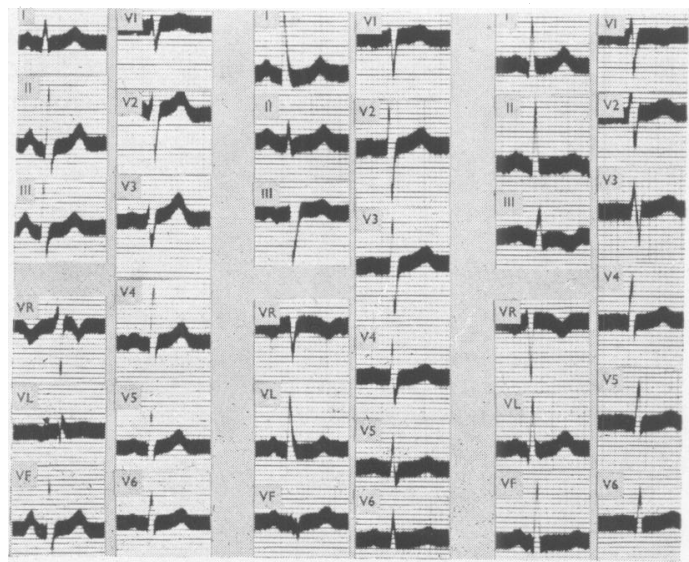

Fig. 11.-Semi-vertical heart. In this case, unlike in Fig. 9, the standard leads suggest the heart is vertical.

Fig. 12.- Semi-horizontal heart. The $R$ wave is tall in $\mathrm{VL}$ and the complexes are small in VF.

FIG. 13.- Intermediate heart. The ventricular complexes of VL and VF are similar in form and size, and resemble those of $\mathrm{V}_{5}$ and $\mathrm{V} 6$.

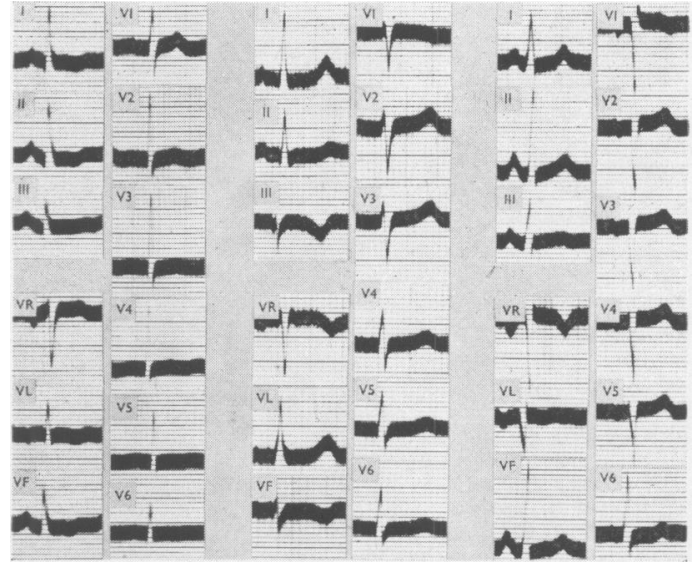

Fig. I4:- Indeterminate heart. There is no obvious relationship between the ventricular complexes of the $\mathrm{V}$ limb leads and $\mathrm{V}$ chest leads. In the illustration VL resembles VF somewhat, and these two leads also resemble complexes from the right and left of the precordium.

FIG. 15.-Normal amount of rotation around the lorgitudinal axis. The transitional point (T.P.) is seen to be between $V_{3}$ and $V_{4}$. A diminutive $Q$ wave car be discerned from leads which face the left side of the ventricular septum.

FIG. 16.-Considerable amount of clockwise rotation around the longitudinal axis. The T.P. lies. between $\mathrm{V}_{5}$ and $\mathrm{V} 6$. The heart is vertical.

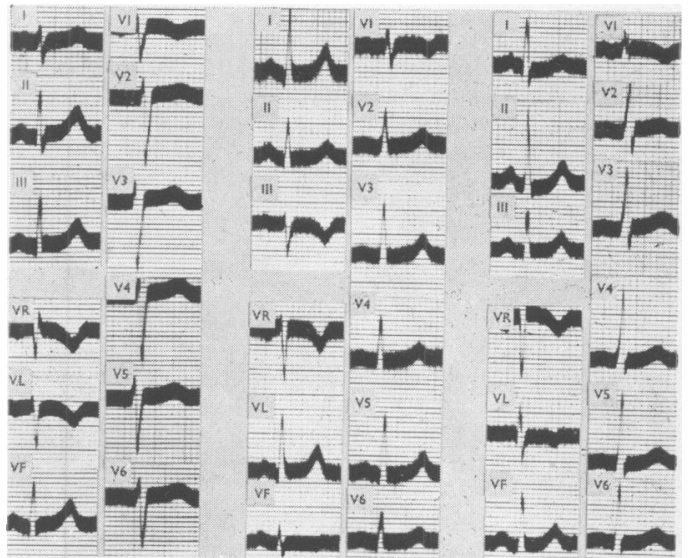

FIG. 17.-Extreme degree of slockwise rotation. The T.P. is not seen because it lies beyond V6. Lead VL comes to face the surface of the right ventricle instead of the left, and therefore shows an RS pattern. Lead VR tends to face the back of the heart and therefore shows a $Q R$ pattern with a negative $T$ wave.

Fig. 18.-Considerable amount of anti-clockwise rotation. The T.P. is seen to lie between $V_{1}$ and $V_{2}$.

FIG. 19.-Extreme degree of anti-clockwise rotation. The T.P. is not seen because it lies beyond VI. 


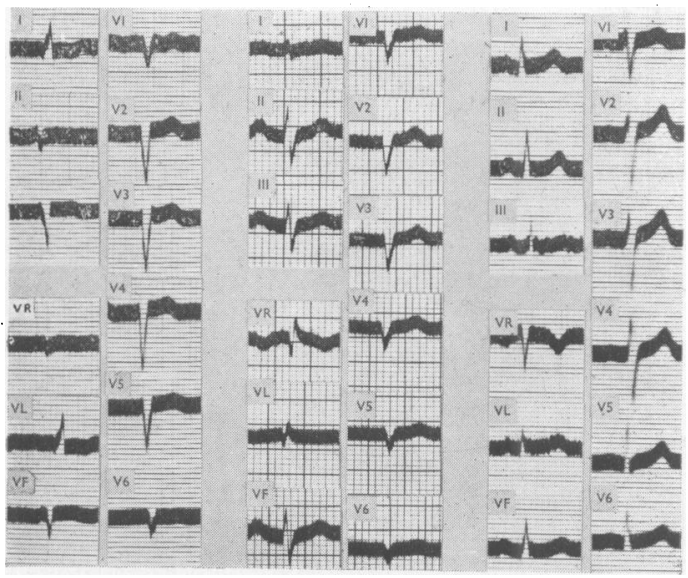

Fig. 23.-Left ventricular hypertrophy. The $R$ waves in $V_{1}$ and $V_{2}$ are even smaller than normal but the $\mathrm{S}$ waves are deeper than normal. In $\mathrm{V}_{5}$ and V6 the peak of $R$ is abnormally late, $R$ is too tall, the RS-T segment is depressed, and T is inverted.

Fig. 24.-The standard leads suggest that the heart is vertical, but as all three $T$ waves are inverted it is not possible to say which, if either, ventricle is hypertrophied. The $\mathrm{V}$ chest leads show that the left ventricle is hypertrophied.

Fig. 25.-Right ventricular hypertrophy. In $V_{I}, V_{2}$ and $V_{3} R$ is abnormally large and its peak is late, QRS is a little widened and T is inverted. A small primary $R$ and $S$ wave is just visible in VI.
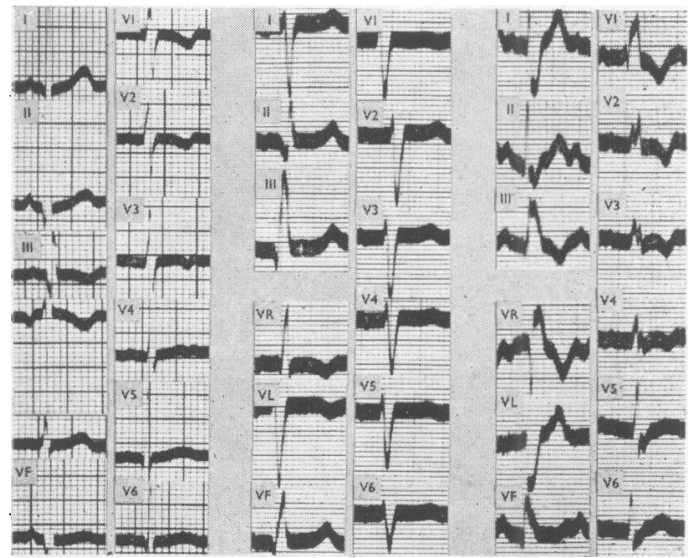

Fig. 20.-Extreme clockwise rotation in a horizontal heart. T'his rather unusual position is deduced from the facts that the VL and VF leads show the heart to he horizontal yet the $\mathrm{V}$ chest leads show the heart to have an extreme clockwise twist. Auricular fibrillation is present.

FIG. 21.-Th: heart is vertical and has extreme clockwise rotation around the longitudinal axis, the T.P. being beyond V6. In addition, the apex is rotated b ackwards. This causes VF to reflect an RS pattern and VR and VL a QR form.

Fig. 22.-The cardiogram is quite normal, yet at the time the record was taken severe hypertensive heart disease was present, B.P. 195/100, and the large left ventricle was confirmed radiologically.

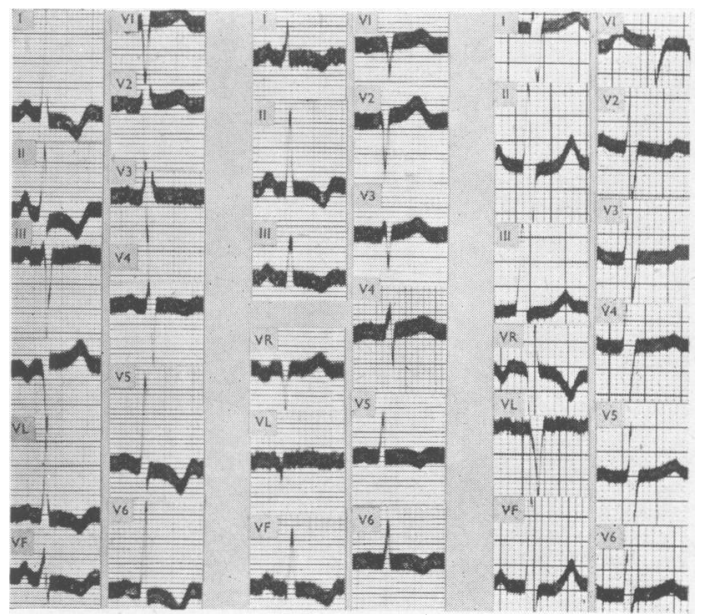

FIG. 26.-Cardiogram from a normal child aged six years. Comparison with Fig. 25 will show how closely it resembles that produced in adults by right ventricular hypertrophy.

FIG. 27.-Congenital dextrocardia. VR resembles a normal VL complex, namely a QR pattern, and VL resembles the usual VR, namely an RS form. The $\mathrm{V}$ chest lead complexes resemble those found at mirror image sites from the right chest in normal persons.

FIG. 28.-Complete right bundle-branch block. The QRS complex is prolonged to 0.12 sec. or more. $V_{I}$ and $V_{2}$ show a broad notched $R$ wave which is preceded by a very small primary $R$ and $S$ wave. In $V_{5}$ and $V_{6}$ the $R$ wave is slender and followed by a broad S. It is seen that the pattern of right bundle-branch block can closely similate that of right ventricular hypertrophy. 
FIG. 29.- Incomplete right bundle-branch block. This cannot be diagnosed from standard leads. In this record they are, in fact, misleading as considerable left axis deviation is present. QRS is of longer duration than $0.08 \mathrm{sec}$. (but not more than 0. I I sec.), and a secondary $R$ wave occurs in lead $V_{I}$.

FIG. 30.-Complete left bundle-branch block. QRS is at least of $0.12 \mathrm{sec}$. duration. In $V_{1}$ and $V_{2} R$ is small or absent and a deep broad $\mathrm{S}$ is present. In $\mathrm{V}_{5}$ and V6 a broad R occurs which may be notched or bifid.

Fig. 3r.-The T wave in Lead $\mathrm{I}$ is very flat, almost isoelectric, but the V limb leads show that this is of no pathological significance, being merely due to the semi-vertical position of the heart. All the $\mathrm{V}$ chest lead $T$ waves are upright.

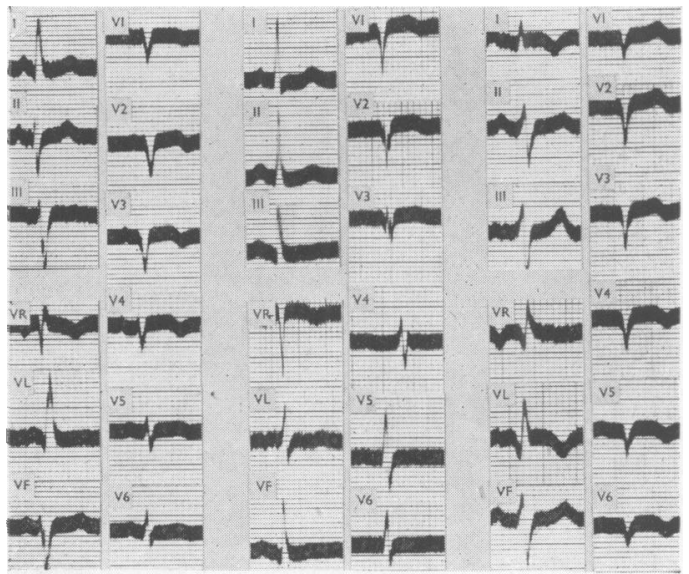

Fig. 35.-From inspection of Lead III posterior infarction might be suspected, especially as $T_{2}$ is rather low and $T_{I}$ rather tall and pointed. But Lead VF shows that none has occurred.

FIG. 36.-Posterior infarction. The typical changes are seen in Leads VF and III. Although the V chest leads are often disappointing, they may show abnormally tall and symmetrical $T$ waves, as in this case.

FIG. 37.-Postero-lateral infarction. In addition to infarction changes in VF and III, $\mathrm{V}_{4}$ to $\mathrm{V} 6$ also show them. Sometimes TI may be inverted too.

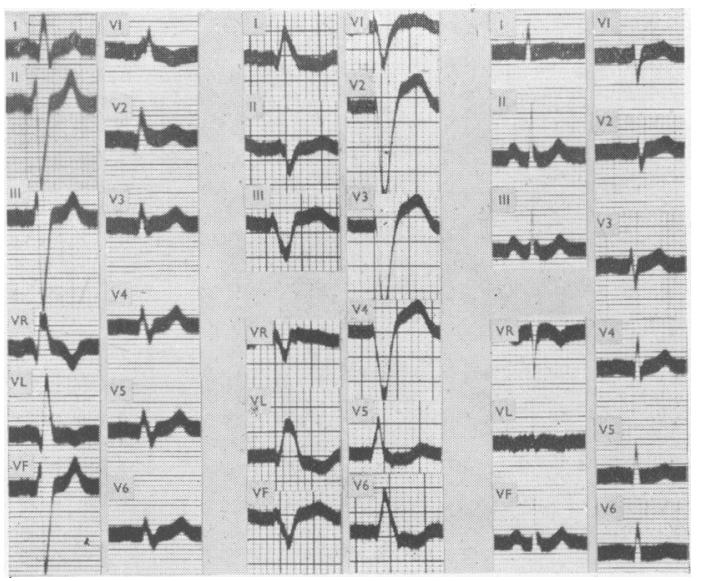

FIG. 32.- Strictly anterior infarct. The infarct does not reveal itself in the standard leads. $\mathrm{V}_{\mathrm{I}}$ to $\mathrm{V}_{4}$ are chiefly affected.

FIG. 33.-Antero-septal infarct. The extension of the infarct into the septum has involved the right branch of the bundle of $\mathrm{His}$, so that, in addition to the widening of QRS due to the block, a deep $Q$ wave, elevated RS-T segment, and inverted $T$ wave is seen in $V_{I}$ and $V_{2}$. No signs of infarction are seen in either the standard leads or the $\mathrm{V}$ limb leads.

FIG. 34.-Antero-lateral infarct. Maximal changes are seen in $\mathrm{V}_{4}$ to $\mathrm{V6}$, but often all chest leads are involved. $\mathrm{T}$ is inverted always in VL and $\mathrm{I}$.

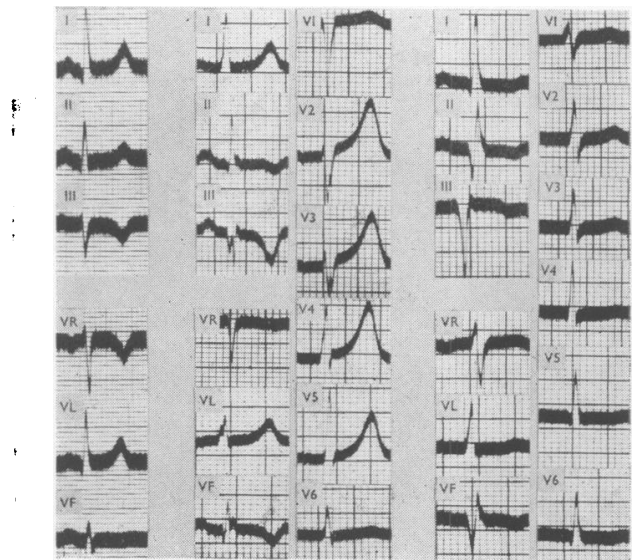




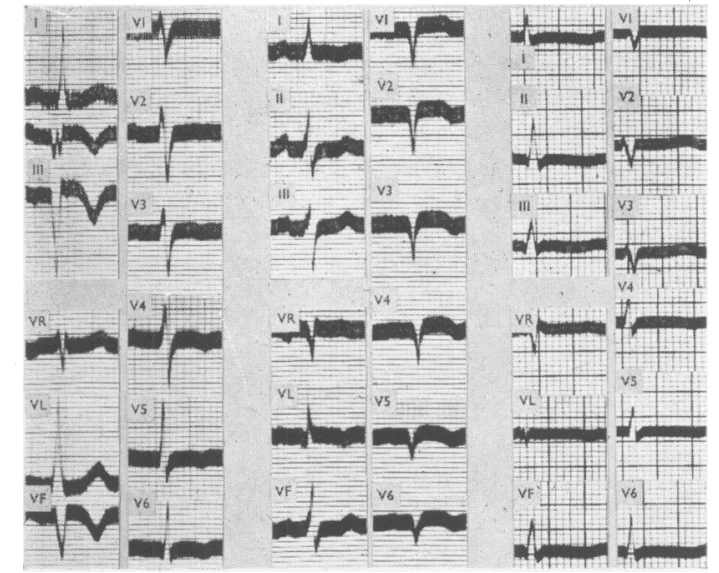

Fig. 41.-Recent anterior infarction and old posterior infarction. The chest leads indicate recent anterior infarction, but in Leads VF and III the deep wide $Q$ indicates old posterior infarction. $T$ in $V F$ may become upright. Two distinct attacks of cardiac pain occurred with an interval of two years between them.

FIG. 42.-Recent posterior infarction and old anterior infarction. Changes in VF and III suggest recent posterior infarction, but the chest leads show inverted $T$ waves. The RS-T segment in $V_{3}$ to V6 is depressed, presumably due to the recent posterior infarct. Autopsy confirmation was obtained.

FIG. 43.-Right bundle-branch block and posterior cardiac infarction. The chest leads show right bundle-branch block only, but leads VF and III show the deep and wide $Q$ wave and elevation of the RS-T segment typical of infarction.

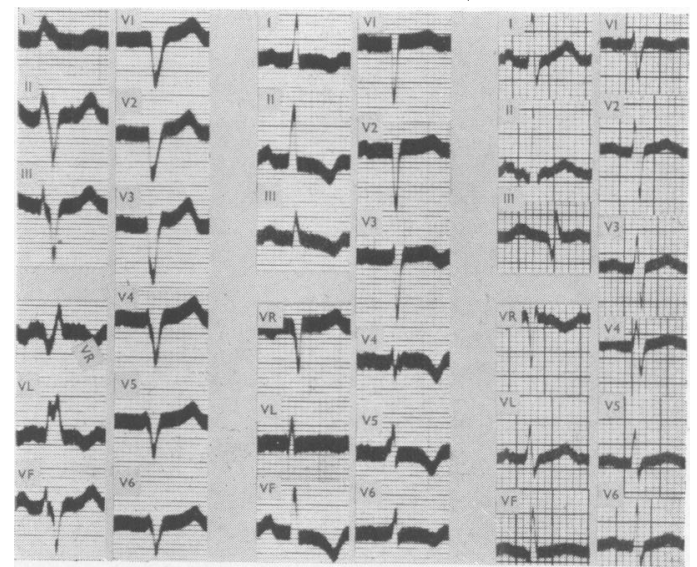

FIG. 38.-Septal infarction. The standard leads suggest $c$ posterior infarction has occurred, but the chest $\Rightarrow$ leads show signs of anterior infarction.

FIG. 39.-Ventricular aneurysm. The displacement of the RS-T segment suggests a recent current of $\frac{\bar{\sigma}}{\bar{D}}$ injury, but the patient had had no pain during the $\frac{\sigma}{\sigma}$ eight months preceding the cardiogram. . Autopsy $\mathbb{Q}$ revealed a large ventricular aneurysm and no evidence of recent infarction.

FIG. 40.-Although all the $T$ waves are very low, flat, $\overrightarrow{0}$ or inverted, the patient had experienced no cardiac $\vec{\omega}$ pain. He was myxoedematous.

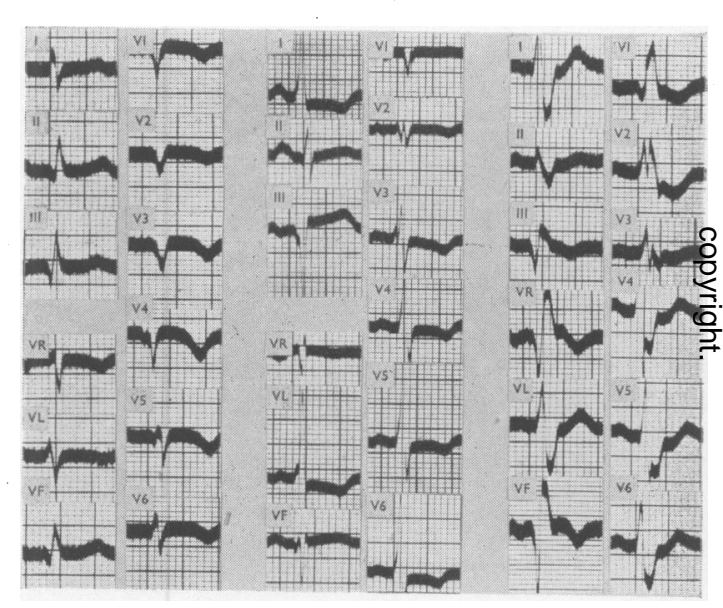

FIG. 44.-Left bundle-branch block and anterior cardiac infarction. Only signs of the block are present, the infarction signs being completely masked.

FIG. 45.-From the same case as Fig. 44. The bundlebranch block has remitted, and an infarct involving the apical region of the left ventricle is now revealed.

Fig. 46.-Pulmonary embolism. The deep $\mathrm{SI}_{\mathrm{r}}$ and $\mathrm{Q}_{3}$ are typical. The absence of a deep $Q_{1}$ in VF excludes posterior cardiac infarction. 
wave in VL is said to be upwards in clockwise rotation of most extreme degree. Fig. I 8 illustrates considerable anti-clockwise rotation and the transitional point is between $V_{I}$ and $V_{2}$. In Fig. I9 extreme anti-clockwise rotation is illustrated and no transitional point is seen. If the heart with much anti-clockwise rotation is horizontal, $\mathrm{T}$ can be inverted in VI, without implying ventricular hypertrophy and, of course, the chest leads will show T's which are all upright. Fig. 20 illustrates a rather uncommon combination, namely extreme clockwise rotation with a horizontal heart. The rotation is estimated from the chest leads, but from the limb leads the heart is seen to be horizontal.

It is seen that $\mathrm{V}$ leads which face the left side of the ventricular septum almost always show a very small initial $Q$ wave.

Rotation around the transverse axis. This type of rotation, because it is at right angles to the frontal plane, would not be expected greatly to change the chest leads. If the apex of the heart is rotated backwards sufficiently, Lead VF, which ordinarily faces the surface of the left ventricle when the heart is vertical, now faces the right ventricle. Its $\mathrm{QR}$ pattern therefore changes to an RS pattern. The ' upper' leads (VR and VL) tend to face the back of the heart if the apex is tilted backwards and therefore will tend to show a QR pattern, although this is probably not as reliable as the leg lead. Fig. 2 I illustrates a vertical heart with considerable clockwise rotation around its long axis. In addition, some backward rotation of the apex is almost certainly present because Leads VR and VL both show a QR pattern and VF shows an RS complex.

The appearances seen in forward rotation of the apex are not fully worked out, and from anatomical considerations it would seem to the author that less alteration of the limb leads than occurs in backward rotation would be expected. Goldberger (1947) maintains that if considerable forward rotation does occur in a horizontal heart it is a sign of left ventricular hypertrophy.

\section{Cardiac Hypertrophy}

Sometimes typical cardiographic appearances due to cardiac hypertrophy appear, but it must be admitted that in many other apparently identical cases with cardiac hypertrophy the electrocardiogram is perfectly normal. The $\mathbf{P}$ wave may be typical of auricular hypertrophy although the QRS complex remains normal, thereby suggesting indirectly that ventricular hypertrophy is, in fact, present.

Fig. 22 is a normal electrocardiogram from a patient in left ventricular failure (B.P. 195/IIO) with undoubted left ventricular hypertrophy which was confirmed radiologically.

\section{Auricular Hypertrophy}

Because of the greater muscle mass the $P$ wave produced by a hypertrophied auricle is taller, and because the impulse has a longer path of travel the width of the $P$ wave is increased. Auricular hypertophy is suggested if the width of the $P$ wave in the $\mathrm{V}$ limb leads is $0 . \mathrm{I}$ sec. or more and its height $2.5 \mathrm{~mm}$. Leads VR and VF reveal auricular hypertrophy best. . The wave may be notched or biphasic, but this by itself may be a feature of the normal $\mathrm{P}$ wave.

\section{Ventricular Hypertrophy}

The cardiographic signs of hypertrophy are some six in number :-

I. The increased mass of muscle causes QRS to be of high voltage. This has led various authors to give measurements for the height of $\mathrm{R}$ beyond which hypertrophy may be diagnosed. For example Goldberger (I947) maintains that when the heart is horizontal, if the height of the $\mathrm{R}$ wave in $\mathrm{VL}$, as measured from the upper edge of the base line to the peak, is $13 \mathrm{~mm}$. or more, it indicates left ventricular hypertrophy ; or if in a vertical heart it is $20 \mathrm{~mm}$. or more in lead VF. But great caution should be exercised in attaching much importance to this as a single finding as East (1947) has shown how great the effect of respiration is on the amplitude of all the complexes, particularly the QRS.

2. The thickened ventricular muscle results in the impulse taking longer to spread through its wall, and this causes a widening of QRS so that the appearance may resemble that of bundle-branch block. Wilson and his associates (1947) are confident that this appearance does not represent bundle-branch block, either complete or incomplete, but Rasmussen and Moe (1948) suggest that the left bundle-branch block cardiogram is five times more often due to enlargement of the left heart than to a local lesion of the left branch of the bundle. In this connection dilatation is deemed to be more important than hypertrophy.

3. Because of the thick ventricular wall the impulse arrives late at the ventricular epicardium, therefore the intrinsic deflection is late in leads overlying the hypertrophied muscle. In left ventricular hypertrophy the intrinsic deflection is late in Leads $\mathrm{V}_{5}$ and V6, and in right-sided hypertrophy in Leads VI and V2.

4. Because the epicardial surface is stimulated late it also returns to the resting state late, and tends to return to it in the same order as it was stimulated, the situation being analogous to that of a simple muscle strip (Fig. I, A to E). Conse- 
quently the $\mathrm{T}$ waves point in a direction opposite to that of the QRS, and the RS-T segment is depressed. Thus in left ventricular hypertrophy $\mathrm{T}$ is commonly inverted in $\mathrm{V}_{4}, \mathrm{~V}_{5}$ and $\mathrm{V} 6$ and the RS-T segment is displaced downwards (Fig. 23), and in right ventricular hypertrophy $\mathrm{T}$ in $\mathrm{V}_{1}, \mathrm{~V}_{2}$, and sometimes $\mathrm{V}_{3}$ is inverted (Fig. 25). Bain and Redfern (1948) state that in right ventricular hypertrophy the $T$ waves may be inverted in any of the chest leads but this is not in accord with our experience. In normal $\mathrm{V}$ limb leads the RS-T segment may begin $0.5 \mathrm{~mm}$. below the isoelectric level or $1.0 \mathrm{~mm}$. above it, and in V chest leads it may begin up to $2.0 \mathrm{~mm}$. above or below the base line.

5. In left ventricular hypertrophy the normally small $R$ waves of $V_{I}$ and $V_{2}$ are even smaller and the normally deep $\mathrm{S}$ waves in these leads are still deeper. In right ventricular hypertrophy in Leads $V_{I}$ and $V_{2}$ the $R$ wave is abnormally large. There may be a small $\mathrm{R}$ wave followed by a primary $\mathrm{S}$ wave, and sometimes these small primary deflections cause a notch on the upstroke of $R$ in Leads VI and V2.

6 . In left ventricular hypertrophy the transitional zone may be displaced to the right, and the heart is commonly horizontal with a tall $\mathrm{R}$ wave in VL. In right ventricular hypertrophy the transitional zone is frequently displaced to the left and the heart is commonly vertical with a tall $\mathrm{R}$ wave in VF (Fig. 25).

Standard leads may suggest that the heart is vertical, or even right axis deviation may be present, and the $\mathrm{V}$ limb leads may confirm this electrical position, yet $\mathrm{V}$ chest leads show left ventricular hypertrophy. VF comes to face the left ventricle and therefore shows a $Q R$ pattern (Fig. 24). Bain and Redfern (1948) state that the combination of signs of left ventricular hypertrophy in the chest leads and a vertical heart would seem to indicate hypertrophy of both ventricles, but we have come across instances of pure aortic stenosis giving this type of picture.

In children the cardiogram resembles that of right ventricular hypertrophy in adults. The $\mathrm{R}$ wave may be tall and the $\mathrm{T}$ wave inverted in $\mathrm{VI}_{1}, \mathrm{~V}_{2}$ and $\mathrm{V}_{3}$ (Fig. 26).

Help can be obtained in the diagnosis of congenital heart lesions from a knowledge of the appearances produced by right ventricular hypertrophy. For example, if right ventricular hypertrophy is present it rules out such diagnoses as uncomplicated persistent ductus arteriosus or subaortic stenosis. Dextrocardia may be diagnosed when Lead VR resembles a normal VL lead, and VL resembles a normal VR. The usual VI-V6 complexes appear abnormal but are similar to those found over the right chest in normal people

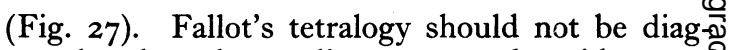
nosed unless the cardiogram reveals evidence of right ventricular hypertrophy.

\section{Bundle-branch Block}

Of recent years doubt has been cast on the existence of the branches of the bundle of His ap distinct histological structures, but however this․ㅡ. may be it is certain that they perform physio $\frac{\bar{D}}{\vec{D}}$ logically as though they were single strands of tissue. The finding of bundle-branch block does not, by itself, necessarily imply the presence of cardiac disease. It is sometimes found in health ${ }_{i}^{\circ}$ right bundle-branch block being more often found than left.

In bundle-branch block the intrinsic deflection is delayed on the side of the lesion but occurs a the usual time (' early') on the healthy side. Theiv prolonged QRS is usually of slightly longer dura-i tion than in the standard leads. The curves of right and left bundle-branch block are not the exact reverse of each other owing to the fact that the wall of the right ventricle is not as thick as that of the left. The block may be complete or incomplete, although left incomplete bundle-branch block is impossible to diagnose with certainty as the appearance is identical with that seen in lefteo ventricular hypertrophy with prolongation of QRS. Incomplete bundle-branch block may diagnosed when QRS is more than $0.08 \mathrm{sec}$. not more than 0. I I sec. It is probable that curves which do not conform to either right or left bundle-branch block are due, in some cases, to ap block of both bundles.

\section{Right Bundle-branch Block}

As stated earlier, normally the left side of the ventricular septum is the first to be stimulated:This is still the case in right bundle-branch block? so that electrodes facing the surface of the right: ventricle record an upward deflection, and those facing the left ventricle a downward one. Buig because while this septal activity is occurring the impulse is spreading through the unblocked left ventricle in a direction opposite to its spread through the septum, it tends to counterbalances the septal activity and therefore decreases the initial deflection and causes a downstroke in right-sided electrodes and an upstroke in left sided electrodes. By this time, the blocked right ventricle is being stimulated, and this cause an upstroke in right-sided electrodes and a downstroke in left-sided electrodes. When stimulation is complete the deflection returns to the base line⿻ To sum up, right-sided electrodes show a wide $\mathrm{RSR}^{\prime}$, or RSR'S', and left-sided electrodes show wide $\mathrm{QRS}$. The $\mathrm{T}$ waves are usually inverted in recordings from right-sided electrodes, and up $\underset{\square}{\stackrel{D}{D}}$ 
right in left-sided electrodes (Fig. 28). It is seen that the pattern in right bundle-branch block can closely simulate that of right ventricular hypertrophy. A broad, notched R occurs in VI and often in V2. Often there is a tiny primary $R$ wave and a succeeding $S$ wave, which are followed by a large secondary $\mathrm{R}$. In left-sided leads a slender $\mathrm{R}$ is followed by a broad $\mathrm{S}$. $\mathrm{R}$ may be preceded by a small $Q$ wave, but if $Q$ is deep in $V_{I}$ and $V_{2}$ it usually means the septum has been infarcted (see later, anteroseptal infarct). The intrinsic deflection begins at the apex of the second component. As one moves from $V_{I}$ to $\mathrm{V} 6$ the first component grows rapidly in size, and finally becomes a tall thin $\mathrm{R}$ wave, while the second component rapidly diminishes and becomes a broad but often shallow S wave (Fig. 28). Regardless of the position of the heart, in almost all cases of right bundle-branch block a deep wide $S$ wave appears in Lead I. It has nothing to do with right axis deviation and results from the deep wide $\mathrm{S}$ wave in VI.

In incomplete right bundle-branch block embryonic R waves appear in VI. Recently Wilson ( I947) has stated that the diagnosis of incomplete right bundle-branch block is only justifiable when, in addition to prolongation of $\mathrm{QRS}$, there is a definite secondary $\mathrm{R}$ wave in both Leads $\mathrm{V}_{\mathrm{I}}$ and in a lead from the tip of the ensiform cartilage. Incomplete bundle-branch block cannot be diagnosed from standard leads (Fig. 29). Occasionally complete and incomplete bundlebranch block alternate in a single tracing.

\section{Left Bundle-branch Block}

The $R$ wave is small or absent in $V_{I}$ and V2, unlike in left-sided leads in right bundle-branch block, and a deep broad S occurs. In left-sided leads a large, broad, notched $\mathrm{R}$ occurs. The position of the transitional point is very variable (Fig. 30). Bain and Redfern (I948) point out that the terms ' concordant' and 'discordant', as applied to the standard leads in left bundle-branch block, merely mean that the heart is vertical in the former case and normai or horizontal in the latter. When left bundle-branch block is present it may be impossible to diagnose also left ventricular hypertrophy, but, if a small $Q$ wave is present from leads facing the surface of the left ventricle, hypertrophy may be assumed. If the $\mathrm{Q}$ wave in this position is large it may be the result of a transseptal infarct in addition to left bundle-branch block according to Wilson and his associates (1945).

It will be seen later that the presence of left bundle-branch block can completely conceal evidence of infarction.

The heart is usually horizontal in left bundle- branch block, but it may be vertical. Although it is rare to find a vertical heart with left bundlebranch block, it may cause the standard leads to show an appearance resembling right bundlebranch block when in fact left bundle-branch block is clearly shown to be present by the $\mathrm{V}$ chest leads. Occasionally, right and left bundlebranch block complexes alternate in a single tracing.

\section{Cardiac Infarction}

It is convenient to consider the ways in which the normal QRST may be altered in myocardial infarction under four headings :-

I. The $Q$ wave may become abnormal both in depth and width.

2. The $\mathrm{R}$ wave may become smaller, or may be shown as a notch on the $\mathrm{Q}$ wave, or may disappear altogether.

3. The RS-T segment may be either elevated or depressed.

4. The $\mathrm{T}$ wave is inverted and becomes abnormally symmetrical in shape.

Normally the $\mathrm{T}$ wave is asymmetrical with the apex nearer the end than the beginning of the hump.

It is not clear, even today, in which precise order these changes appear. The school led by Wilson maintain that segment shift is the earliest event, but Bayley and his co-workers are of the opinion, from experimental work, that $T$ wave inversion without segment shift may be the first abnormality. The latter observation would appear to be confirmed, at least for some cases, by a recent paper by East and Oram (1948) who describe a special group of patients with undoubted cardiac pain associated with $T$ wave inversion but without segment shift. Dressler and Roesler (1947) maintain that the very earliest sign of infarction, present for not more than 12 hours after the onset of the symptoms, is the appearance of abnormally tall upright $\mathrm{T}$ waves, but this as yet awaits confirmation.

\section{Q Wave Changes}

Although it is possible for infarction to be present without the appearance of pathological $Q$ waves, when they do appear it is evidence that actual death of muscle has occurred. Electrical potentials that normally are produced by such an area before infarction causes necrosis, disappear, and an electrode overlying such ar area will not record any current from it. It will, however, pick up the potentials from the underlying cavity " as though a hole were cut in the ventricular wall' (Wilson, 1944). Consequently, as seen earlier, the spread of the impulse through the septum will, in left-sided electrodes, cause the 
usual negative deflection ( $Q$ wave), but the up ward deflection which rapidly follows, due to the impulse passing through the left ventricular wall, will be absent or reduced because part of the wall is dead. In addition, as the cavity of the right ventricle is negative, the $Q$ wave will be deeper and wider than normal. The width of $Q$ is measured from the upper edge of the base line, and in leads facing the left veritricle it normally measures less than $0.04 \mathrm{sec}$. The depth of $\mathrm{Q}$ is measured from the lower edge of the base line to its lowest point or nadir, but criteria for its depth are difficult to lay down as they depend on so many factors. Goldberger ( $194 \%$ ) claims that in Lead VL, if anterior infarction is present, the depth of $Q$ is usually 50 per cen $i$. or more of the amplitude of $R$. Myers and Oren (1945) state that it is strong evidence of posterior infarction when the $Q$ wave in Lead VF is inore than 25 per cent. of the amplitude of IR. But East has shown (1947) that respiration can affect the depth of $Q$ waves so markedly that it c an be several millimetres deep at one end of a 1 ra $:$ ng and absent at the other.

\section{R Wave Changes}

If the outer layers of muscle in an infarcted region remain undamaged, $R$ may be present but of sub-normal size, and actually infarcts of the left ventricle are usually more extensive in the inner layers of muscle. If necrosis is more transmural, but a little muscle remains alive in the centre of it, all that may remain of the $R$ wave is a notch on the downstroke or upstroke of a deep wide QS wave. If $R$ is tall it suggests that the electrode is facing the margin of the infarct.

\section{RS-T Segment Changes}

As previously mentioned, in $\mathrm{V}$ limb leads the segment may be displaced up to $0.5 \mathrm{~mm}$. below the isoelectric level or $1.0 \mathrm{~mm}$. above it. In V chest leads it can begin as much as $2 \mathrm{~mm}$. above or below it. There are many theories concerning the production of pathological segment shift, but all agree that its cause is injury to the muscle. A $\mathrm{V}$ lead that faces the injured area will show an abnormally elevated RS-T segment, and one which faces the opposite direction will show an abnormally depressed ore. The segment may run horizontally or may have an upward or downward convexity. The $\mathrm{T}$ waves are absorbed into the displaced segment at first and cannot be recognized. Unusually prolonged RS-T displacement has an unfavourable outlook according to Wilson (1944). If the displacement is more or less permanent it is often associated with ventricular aneurysm.

It will be seen from Fig. 2 that the effect an infarct has on the ventricular complex is roughly气 proportional to the magnitude of the solid angle 3 which its epicardial surface subtends at that point. If the observer looks through the cone from its. apex, and sees the epicardial surface of the infarct, $\overrightarrow{\overrightarrow{2}}$ the RS-T segment displacement is upward ; if hes sees the endocardial surface, the displacement is $\frac{C}{\sigma}$ downward.

\section{$T$ Wave Changes}

The $\mathrm{T}$ waves are often abnormally large and symmetrical, and develop in a direction opposite. to that of the RS-T segment displacement. If the $\overrightarrow{\vec{\omega}}$ electrode is facing the endocardial surface of theo infarct it may yield upright $T$ waves which are too $\overline{0}$ large and too symmetrical, and this is sometimes 3 . seen in anterior chest leads overlying a posteriorio infarct (Fig. 36). The Q-T interval is commonly prolonged in infarction.

Before interpreting $T$ wave changes as theresult of ventricular ischaemia, great care must be $\mathrm{G}$ taken to exclude the effect of previous digitalis? therapy. Similarly, a flat or somewhat inverted Tin Lead I may be merely due to the fact that the heart is in the vertical or semi-vertical position (Fig. $3 \mathrm{I}$ ). It is true, as is pointed out by Dressler $\overrightarrow{0}$ (1943), that if the height of TI is less than height of TIII, anterior infarction is likely, bit: this is by no means always the case. The autharo has never seen an inverted $T$ wave in Lead $I$ in health. Myxoedema must also be borne in mind as a cause of pathological T waves (Fig. 40). Lapin $\frac{0}{\mathrm{D}}$ ( 1947$)$ has drawn attention to other causes of $a \varrho$ diminished amplitude.

\section{The Position of the Infarct}

One of the greatest uses of unipolar cardiography is the exact determination of the site of a particularo infarct. It is not claimed that there is any specialclinical significance in such exact localization, and 3 for that matter the treatment of an infarct is the same whatever its position, but the whole object of 3 such detailed exploration is to show that, at times, it may be essential to take at least 12 leads before unequivocal evidence of infarction is found. If $\frac{D}{O}$ this is not done infarction will certainly be missed.

There are two main cardiographic patterns in one is due to so-called anterior infarction, which is more often antero-lateral in distribution, and the other is due to so-called posterior infarction, which ${ }^{\omega}$ actually involves more of the inferior. (diaphragmatic) surface of the heart than the posterior. $A_{C}$ third type, in which the septum is involved from front to back, has recently been described by Roesler and Dressler (1947). But these patterns, 뭉 characteristic although they are, may be altered $\mathbb{\nabla}$ by such complicating factors as the position of the $\frac{?}{\mathrm{O}}$ heart, which itself may be altered by the presence 
of the infarct ; by the presence of a ventricular aneurysm ; by the appearance of multiple infarcts ; by the presence of bundle-branch block, either caused by the infarct or due to the large left ventricle which is commonly present; by the complication of pericarditis over the infarcted area ; and by the occurrence of pulmonary embolism. If digitalis has been administered during the three weeks preceding the infarction caution must be exercised before ascribing $\mathrm{T}$ wave inversion to local ventricular ischaemia.

\section{Uncomplicated Gardiac Infarction}

I. Strictly anterior. These infarcts are anteroseptal in distribution, and no involvement of the right branch of the bundle of His has occurred. The chief leads affected are $V_{1}, V_{2}$ and $V_{3}$, and the particular importance of this group is that the standard leads are often normal (Fig. 32). Many of these lesions must have been missed in the era prior to unipolar lead exploration, and it is perhaps no exaggeration to say that the greatest practical value of $\mathrm{V}$ leads is in the detection of these infarcts, which are common.

2. Antero-septal with involvement of the right bundle-branch. As in the first group, $\mathrm{V}_{1}, \mathrm{~V}_{2}$ and $\mathrm{V}_{3}$ are involved. In addition $\mathrm{QRS}$ is widened and a deep $Q$ appears in $V_{1}, V_{2}$ and $V_{3}$ together with a late $R$ wave and elevation of the RS-T segment with bowed inverted $T$ waves (Fig. 33). In leftsided leads a slender $R$ wave occurs and the $T$ waves may be normal. The only hint of infarction in the standard leads may be a widening of the QRS complex, but sometimes $\mathrm{T}_{\mathrm{I}}$ is inverted.

3. Antero-lateral. The maximal changes are found in Leads $\mathrm{V}_{4}-\mathrm{V} 6$ and VL and Lead I (Fig. 34). Sometimes infarction changes occur in VL and I yet the chest leads remain normal, but in the cases which have high antero-lateral infarcts, if the chest leads are recorded from one interspace higher than the usual one, the expected changes will be seen (Wilson, 1946). As the height of the $R$ wave tends to increase as the electrode is moved through $\mathrm{VI}_{\mathrm{I}}$ to $\mathrm{V} 6$ if hypertensive heart disease is present, a diminution in its height is valuable corroborative evidence of infarction.

4. Extensive anterior. This is really a combination of types 1 and 3 . All the chest leads are involved, and $\mathrm{T}$ is always inverted in VL and Lead I. The prognosis in such a case need not be unnecessarily gloomy as cases have been published by East and Oram (1948) where even with widespread lesions the outlook was good and the cardiograms reverted to normal. In such a case the $Q$ wave will be absent or, if present, within normal dimensions.

5. Posterior. The lead which most nearly faces the wave as it advances through the infarcted area is VF. Lead III shows similar changes, which although often more pronounced, are, in a sense, spurious. As Bain and Redfern (1948) point out, it is because Lead III = VF-VI, and VL, faces the tail of the wave. To the depth of $\mathrm{Q}$ in VF will be added in Lead III the reversed R of VL; to the upward deviation of the RS-T junction will be added the reversed depression of the RS-T junction in VL; and to the negative $\mathrm{T}$ of $\mathrm{VF}$ will be added the reversed positive T of VL. The chest leads are most often disappointing in posterior infarction. Theoretically, they would be expected to show changes opposite to those of anterior lesions, having depression of the RS-T segment and excessive and symmetrical elevation of the $T$ waves especially at the right side of the praecordium. These changes (Fig. 36) are, however, uncommon. Lead VF is also of inestimable value when it is not clear whether a ' $\mathrm{Q}_{3} \mathrm{~T}_{3}$ ', curve of posterior infarction, or ' $\mathrm{S}_{3} \mathrm{~T}_{3}$ ' curve due to a transverse heart, is present (Fig. 35 ).

6. Postero-lateral. In addition to the expected changes in Leads VF and III, infarction changes occur also in Leads $\mathrm{V}_{4}, \mathrm{~V}_{5}$ and V6. TI may be inverted too (Fig. 37).

7. Postero-inferior or postero-septal. In this uncommon lesion, in addition to the changes described for posterior infarction, a large $Q$ wave and inverted $T$ wave occurs in VE (recorded from the tip of the ensiform cartilage) and sometimes in VI also.

8. Septal. Roesler and Dressler (1947) have produced convincing autopsy evidence that involvement by infarction of the whole ventricular septum, from front to back, will yield a cardiogram which shows signs of antero-septal infarction in the chest leads while the standard leads will show the appearance of posterior infarction (Fig. 38).

\section{Complicated Gardiac Infarction}

I. Ventricular aneurysm. This results much more commonly from anterior infarction than posterior. There may be no evidence of it cardiographically, but one or two signs may suggest it. Either the RS-T segment displacement persists for months or years without further clinical attacks to account for it (Fig. 39), or the standard leads may show a $\mathrm{Q}_{\mathrm{I}}$, relatively small $\mathrm{RI}_{\mathrm{I}}$ and inverted $T_{1}$, and deep $S_{2}$ and $S_{3}$ (Nordenfelt, 1939). A tall $R$ in VR is present, but the latter appearance is said not to be pathognomonic.

2. Multiple infarction. Suspicion of multiple infarction is justified when, in addition to evidence of recent infarction, the presence of an abnormal $Q$ wave occurs in an unexpected lead. Also, because leads which face normal muscle show depressed RS-T segments, if the first infarct has healed so that it is covered by a layer of muscle, 
a lead over it may show the remains of a $\mathrm{Q}$ wave but, in addition, a depressed RS-T segment. Thus in a recent anterior with old posterior infarction, changes in the chest Leads VL and I will indicate recent infarction whereas Leads VF, II and III will show evidence of an old posterior lesion. The T wave may become upright in Lead VF (Fig. 4I). If recent posterior infarction has occurred in addition to an old anterior infarct, the recent changes will be seen in Leads VF, II and III, but the chest leads will show $Q$ waves due to the anterior lesion although their RS-T segments may be depressed due to the recent posterior lesion (Fig. 42).

3. Generalized pericarditis and infarction. There may be no cardiographic alteration with undoubted pericarditis, either dry or with effusion, although these conditions generally result in a superficial myocardial injury and consequent elevation or depression of the RS-T segment and $T$ wave inversion. But these changes are less than those produced by infarction and generally only last for a few days. Low voltage QRS complexes may occur. If only a localized patch of pericarditis occurs over an infarct the extra injury is not recordable. But if the pericarditis is widespread and anterior infarction is present, Lead VF, which shows often a depressed RS-T segment in anterior infarction, shows an elevated one. Similarly, if generalized pericarditis complicates posterior infarction, although the, RS-T segment in Lead VF will be elvated due to the fact that the electrode is facing muscle injured both by infarction and pericarditis, the anterior leads, VL and $\mathrm{V}_{\mathrm{I}}-\mathrm{V6}$, will also show elevated segments instead of the depressed ones expected with uncomplicated posterior infarction.

If multiple infarction is present generalized pericarditis cannot be diagnosed. It is only safe to diagnose the presence of pericarditis by segment shift and not by $\mathrm{T}$ wave inversion.

4. Bundle-branch block and infarction. Many patie ats who develop cardiac infarction are already hypertensive and may already have, as a consequence of the hypertensive heart disease, a cardiogram typical of left bundle-branch block. On the other hand, the infarct may extend into the region of either the left or right bundle and block them. The detection of both anterior and posterior infarction when right bundle-branch block occurs is generally a simple matter, but when left bundle-branch block occurs it may completely mask the appearances of infarction. If the block is intermittent, and remits for a beat or two, the typical infarction changes may be revealed in these complexes (Figs. 44 and 45 ).

Right bundle-branch block and infarction. Electrodes that face the surface of the infarct record the usual pathological $\mathrm{Q}$ wave, elevated $\mathrm{RS}-\mathrm{T}_{\mathrm{O}}^{\mathrm{N}}$ segment and inverted $\mathrm{T}$ wave, but because of the addition of the right bundle-branch block the QRS complex is 0.12 sec. or more wide, and right $€$. sided chest leads show a wide RSR' and left-sidect electrodes show a wide QRS. In anterior in $\stackrel{5}{\rightarrow}$ farction involving the right bundle, which we have already described as antero-septal infaction, one or more chest leads show a deep wide $Q$, a talf final R, elevated RS-T segment and downward TQ wave; but usually neither the $V$ limb leads nots the standard leads show diagnostic changes and the diagnosis will almost certainly be overlooked if chest leads are omitted (Figs. 33 and 43). In $\vec{\omega}$ posterior infarction complicated by right bundles branch block the opposite state of affairs prevailso namely chest leads usually show changes only of. right bundle-branch block whereas the limb leadss VF and II and III, show the typical deep Q waved and elevated RS-T segment with inversion of the T wave. Sometimes depression of the RS-T $\mathrm{G}$ segment in the $\mathrm{V}$ chest leads may suggest the presence of posterior infarction.

Ieft hundle-branch block and infarction. As mentioned above, left bundle-branch block com monly obscures infarction which is revealed only. if the block remits. We have been fortungte enough to record two such examples, one of whiek is illustrated (Figs. 44 and 45 ). However, pointed out by Sodeman, et al. (1944), sometines in anterior infarction although the chest leads show the typical signs of left bundle-branch block there may be additional $Q$ waves recorded from $\mathbb{B}$ the electrodes overlying the infarct and also in Leads VI, and I. Wilson (I944) has suggesteç that in such cases, apart from the left ventriculas infarct there must be such gross involvement of the ventricular septum that its electrical activity disappears, so that left-sided electrodes are vir 3 . tually facing the negative cavity of the right ven tricle.

5. Digitalis and infarction. Digitalis shortens the Q-T interval, and this is usually accompanied by displacement of the RS-T segment in such ag manner that it tends to point in a direction opposite to that of the QRS complex. This is thought to be due to digitalis causing the musclo to return to the resting state in the same direction? as it was stimulated. The RS-T segmerit ofterf has a characteristic form in that it runs either in a straight line, or with sagging, obliquely down-0 ward and then abruptly rises to the base line Reversal of the direction of the $T$ wave may accom $\frac{}{\infty}$ pany these changes. Fortunately, conditionso which give rise to shift of the RS-T segment oro alteration of the direction of the $T$ wave, such as. ventricular hypertrophy, bundle-branch block and cardiac infarction, continue to do so however $\stackrel{\vec{Q}}{\varrho}$ 
much digitalis is administered. Liebow and Feil (I94I) have shown that if an exercise test is being performed on a patient with a normal cardiogram but who is receiving digitalis, or has been receiving it during the preceding three weeks, care must be exercised in interpreting segment and $T$ wave changes as due to an inadequate coronary blood supply because exercise may bring to light digitalis effect on the cardiogram.

\section{Pulmonary Embolism}

Pulmonary embolism is a common complication of cardiac infarction, but the author can find no record of pulmonary embolism having been diagnosed uneruivocally by discovering the typical cardiographic changes occurring in addition to fhose already present as a result of cardiac intarction. Perhaps the pulmonary embolus is either too small to cause cardiographic changes in these patients, or possibly it is so large that the sudden strain on the heart is too much for the already damaged myocardium, and the patient succumbs before there is time for a record to be taken.

Most commonly, in fact in probably 90 per cent. of cases, no characteristic cardiographic change appears, but in those patients in which both pulmonary arteries are invaded, either by two separate clots or by a single rider embolus, an almost pathognomonic picture occurs. McGinn and White (I935) first reported the typical deep $\mathrm{S}_{\mathbf{I}}$ and deep $\mathrm{Q}_{3}$ appearance; it resembles a mixture of right bundle-branch block and posterior cardiac infarction. Frequently pulmonary embolism is accompanied by complete right bundlehranch block, but it gradually improves and becomes normal after several days. Whether the prominent $S_{1}$ and $Q_{3}$ are always due to right bundle-branch block is not certain-they are probably due to rotation of the heart about its long axis as a result of dilatation of the right ventricle. This is suggested because it is possible to obtain such curves with no evidence of complete or incomplete right bundle-branch block in chest leads. On the other hand, chest leads and unipolar limb leads miy be very helpful. For example, if right bundle branch block is produced, the myocardial anoxaemia which accompanies the pulmonary embolus may result in sub-endocardial necrosis. This will give rise to depression of the RS-T segment in the chest leads and Lead VL, and elevation in VR. Lead VF also shows depression of the RS-T segment which, if posterior infarction were present, would be expected to be elevated. Also, the deep $Q$ wave found in Lead VF in cases of posterior cardiac infarction is never present in cases of pulmonary embolism. Sharp inversion of the $\mathrm{T}$ wave may occur in right- sided chest electrodes, but without the production of pathological $\mathrm{Q}$ waves. Transient changes, characteristically of a step-like ascent, have been described in the level and shape of the RS-T segment.

To sum up, it is seen that the great advantage of unipolar lead cardiography, in fact its raison d'être, is that it goes a long way towards placing clinical cardiography on a rational scientific basis and does away with much of the old empiricism of bipolar leads. For this reason its future use is assured. In addition, as we have seen, it offers immediate advaritages of practical clinical value, such as the correct assessment of equivocal $\mathbf{Q}$ wave changes, or dubious alteration of the RS-T segment or $\mathrm{T}$ wave ; it will reveal the presence of certain anterior and antero-septal infarcts which are otherwise undetectable, and will-reveal anterior infarction in the presence of right bundlebranch block; on the other hand, it will exclude posterior infarction if it is absent but suspected trom Lead III ; pericarditis can be diagnosed in the presence of infarction; the criteria for the diagnosis of unilateral ventricular hypertrophy are more satisfactory, and right ventricular hypertrophy can be diagnosed earlier ; it enables a confident diagnosis of incomplete bundle-branch block to be made when standard leads reveal no evidence of it, and it tells with certainty which bundle is blocked when standard leads may appear to depict the sound bundle as at fault; great clinical help may be obtained in differentiating pulmonary embolism from posterior cardiac infarction; it has rendered obsolete the terms ' concordant' and 'discordant' as applied to burdle-branch block, and made obsolescent the term ' axis deviation.'

To Dr. Terence East I am indebted for much encouragement and practical advice concerning the study of this new method of cardiography, and I have to thank Dr. Mary Holt for help with the selection and preparation of the cardiograms.

\section{BIBLIOGRAPHY}

AMER. HEART ASSOC. (1938), Amer. Heart F., 15, 107, 235. ASHMAN, R., WILDE, W. S., and DRAWE, C. E. (1940), Amer.'F. Physiol., 128, 547.

BAIN, C. W. C., and REDFERN, E. MCV. (1948), Brit. Heart f., I0, 9.

DRESSLER, W. (1943), Amer. Heart $¥ ., 26,313$.

DRESSLER, W., and ROESLER, H. (1947), Ibid., 34, 627.

DURANT, T. M. (1948), Ibid., 35, 1021.

EAST, T. (1947), Personal communication.

EAST, T., and ORAM, S. (1948), Brit. Heart F., 10, 263.

EINTHOVEN, W., FAHR, G., and DE WAART, A. (1913), Arch. ges. Physiol., 150, 308.

EVANS, W. (1 948), Personal communication.

EYCLESHYMER, A. C., and SHOEMAKER, D. M. (I911), 'A Cross Section Anatomy,' New York.

GARDBERG, M., and ASHMAN, R. (1943), Arch. intern. Med., 72, 2 I 0. 
GOLDBERGER, E. (1942 (i)), Amer. Heart f., 23, 483.

GOLDBERGER, E. (1942 (ii)), Ibid., 24, 378.

GOLDBERGER, E. (1944), Ibid., 28, $62 \mathrm{r}$.

GOLDBERGER, E. (1945), Ibid., 29, 369.

GOLDBERGER, E. (1947), ' Unipolar Lead Electrocardiography,' Ist edition, London.

JOHNSTON, F. D., ROSENBAUM, F. F., and WILSON, F. N.

(1943), Mod. Concepts of Cardiovasc. Dis., 12, Nos. 6 and 7.

LAPIN, A. W. (1947), Amer. Heart F. 33, 747.

LEWIS, T., and ROTHSCHILD, M. A. (1915), Philos. Tr. $R$. Soc., London, 206, I8r.

LIEBOW, I., and FEIL, H. (I94I), Amer. Heart F., 22, 683.

MASTER, A. M. (1942), "The Electrocardiogram and X-ray Configuration of the Heart,' 2nd edition, Philadelphia.

McGINN, S., and WHITE, P. D. (1935), F. Amer. med. Assoc., 104,1473 .

MYERS, G. B., and OREN, B. G. (1945), Amer. Heart F., 29, 708. NORDENFELT, O. (1939), Acta. med. Scandinav., 102, 101.
RASMUSSEN, H., and MOE, T. (1948), Brit. Heart f., ro, $14 \overline{\pi_{3}}$ ROESLER, H., and DRESSLER, W. (1947), Amer. Heart f̆., 3\% 817.

SODEMAN, W. A., JOhNSTON, F. D., and WILSON, F. (1944), Ibid., 28, $27 x$.

SODI PALLARES, D., VIZCAINO, M., SOBERON, J., an\& CABRERA, E. (1947), Ibid., 33, 819.

WILSON, F. N., JOHNSTON, F. D. MACLEOD, A. C., an BARKER, P: S. (I934), Ibid., 9, 447.

WILSON, F, N., JOHNSTON, F. D., ROSENBAUM, F, F ERLANGER, H., KOSSMAN, C. E., HECHT, H., COTRIN N., DE OLIVEIRA, R. M., SCARSI, R., and BARKEI P.'S. (1944), Ibid., 27, r9.

WILSON, F. N., ROSENBAUM, F. F., JOHNSTON, F. DF and BARKER, P. S., Arch. del Inst. de Card. de Mexico (1945) I4, 201 .

WILSON, F. N., JOHNSTON, F. D., ROSENBAUM, F. F⿳⺈冖़? and BARKER, P. S. (1946), Amer. Heart $\mathscr{\mathcal { Y }}$., 32, 277.

WILSON, F. N., ROSENBAUM, F. F., and JOHNSTON, F. D. (1947), 'Advances in Internal Medicine,' Vol. 2, New York. $\overrightarrow{\vec{H}}$

\section{FELLA W SHIP TA PASTGRAIUATE MEDICINE \\ l Wimpole street, Lomdon, W.}

THE ANNUAL GENERAL MEETING will be held at the above address at 5.0 p.m. on Wednesday, May 18th, 1949. The Meeting is open to all Members of the Fellowship of Postgraduate Medicine, but not to those who subscribe only to the Post Graduate Medical Journal.

\section{$\boldsymbol{A} \boldsymbol{G} \boldsymbol{E} \boldsymbol{N} \boldsymbol{D} A$}

1. To read the Minutes of the last Annual General Meeting.

2. To (a) receive the Reports of the Hon. Treasurer and Hon. Secretaries.

(b) elect (i) The Honorary Officers*;

(ii) Seven Members* to serve on the Executive Committee;

(iii) The Auditors.

3. Any other business.

* Nominations for the Honorary Officers and for the elected Members of the Executive Committee must be sent to the Honorary Secretaries by April 14th, 1949. 